\title{
Severe Acute Respiratory Syndrome Coronavirus 2 Variants of Concern: A Perspective for Emerging more Transmissible and Vaccine-Resistant Strains
}

\author{
Anacleto Silva de Souza ${ }^{1}$, Vitor Martins de Freitas Amorim ${ }^{1}$, Gabriela D A Guardia ${ }^{2}$, Filipe F dos Santos ${ }^{2,3}$, \\ Henning Ulrich ${ }^{3}$, Pedro A F Galante ${ }^{2}$, Robson Francisco de Souza ${ }^{1}$ and Cristiane Rodrigues Guzzo ${ }^{1, *}$ \\ 1 Department of Microbiology, Institute of Biomedical Sciences, University of São Paulo, São Paulo, Brazil. \\ 2 Centro de Oncologia Molecular, Hospital Sírio Libanes, São Paulo, Brazil. \\ 3 Department of Biochemistry, Institute of Chemistry, University of São Paulo, São Paulo, Brazil. \\ * Correspondence: author: crisguzzo@usp.br and crisguzzo@gmail.com, Cristiane R. Guzzo, Department of \\ Microbiology, Institute of Biomedical Sciences, University of São Paulo, Av. Prof. Lineu Prestes, 1374, \\ Cidade Universitária, 5508-900, São Paulo/SP, Brazil, +55 11 3091-7298; E-mail: crisguzzo@usp.br
}

\begin{abstract}
Novel severe acute respiratory syndrome coronavirus 2 (SARS-CoV-2) variants of concern (VOC) are constantly threatening global public health. With no end date, the pandemic still persists with the emergence of novel variants that threaten the effectiveness of diagnostic tests and vaccines. Mutations in the Spike surface protein of the virus are regularly observed in the new variants, potentializing the emergence of novel viruses with different tropism from the current ones, which may change the severity and symptoms of the disease. Growing evidence has shown that mutations are being selected in favor of variants that are more capable of evading the action of neutralizing antibodies. In this context, the most important factor guiding the evolution of SARS-CoV-2 is its interaction with the host's immune system. Thus, as current vaccines cannot block the transmission of the virus, measures complementary to vaccination, such as the use of masks, hand hygiene, and keeping environments ventilated remain essential to delay the emergence of new variants. Importantly, in addition to the involvement of the immune system in the evolution of the virus, we highlight several chemical parameters that influence the molecular interactions between viruses and host cells during invasion and are also critical tools making novel variants more transmissible. In this review, we dissect the impacts of the Spike mutations on biological parameters such as (1) increase of Spike binding affinity to hACE2; (2) bound time for the receptor to be cleaved by the proteases; (3) how mutations associate with increase of RBD up-conformation state in the Spike ectodomain; (4) expansion of uncleaved Spike protein in the virion particles; (5) increment of Spike concentration per virion particles; and (6) evasion of the immune system. These factors play key roles in the fast spreading of SARS-CoV-2 variants of concern, including the Omicron.
\end{abstract}

Keywords: SARS-CoV-2 variants; transmissibility; viral load; sensitivity to antisera

\section{Introduction}

The severe acute respiratory syndrome coronavirus 2 (SARS-CoV-2) rapidly became a concern due to its fast spreading, causing more than 390 millions cases and 5.7 millions deaths to date [1]. The SARS-CoV-2 genome has approximately 29,900 base pairs that encode four structural proteins, i.e., Spike protein (or S protein), nucleocapsid $(\mathrm{N})$, membrane (M) and envelope (E), in addition to 16 other non-structural proteins [2] (Figure 1A). In particular, the full Spike sequence has 1,273 amino acids, having multiple functional domains distributed in two subunits, S1 and S2 [2] (Figure 1B). The S1 subunit recognizes the human receptor, allowing the virus to initiate its entry into the host cell [3], while the S2 subunit favors fusion of the virus envelope with the host cell membrane, thus facilitating virus entry into the host cell [3]. The $\mathrm{S} 1$ is composed of a $\mathrm{N}$-terminal domain (NTD), a receptor binding domain (RBD), and SD1 and SD2 domains, while the S2 subunit 
is composed by the fusion peptide (FP), the heptapeptide repeat sequences 1 (HR1) and 2 (HR2), a transmembrane domain (TM), and an intravirion, palmitoylated cysteine-rich Cterminal domain, often referred to as the cytoplasmic domain or tail (CT) [3][4][5-7]

The functional role of $\mathrm{S} 1$ is associated with the NTD, which helps the virus to adapt to host or environmental conditions. The RBD recognizes and binds to human angiotensin-converting enzyme 2 (hACE2) [3]. The functional role of $S 2$ is associated with the FP, responsible for the insertion of S2 into the target cell's membranes [8][3]. The HR1 and HR2 form a bundle of helices responsible for the membrane fusion of the virus envelope and the host cell's membrane into close proximity [9]. The TM is important for Spike protein trimerization and membrane fusion. The CT anchors the trimer in the viral membrane and it is also involved in membrane fusion [8] (Figure 1).

a)

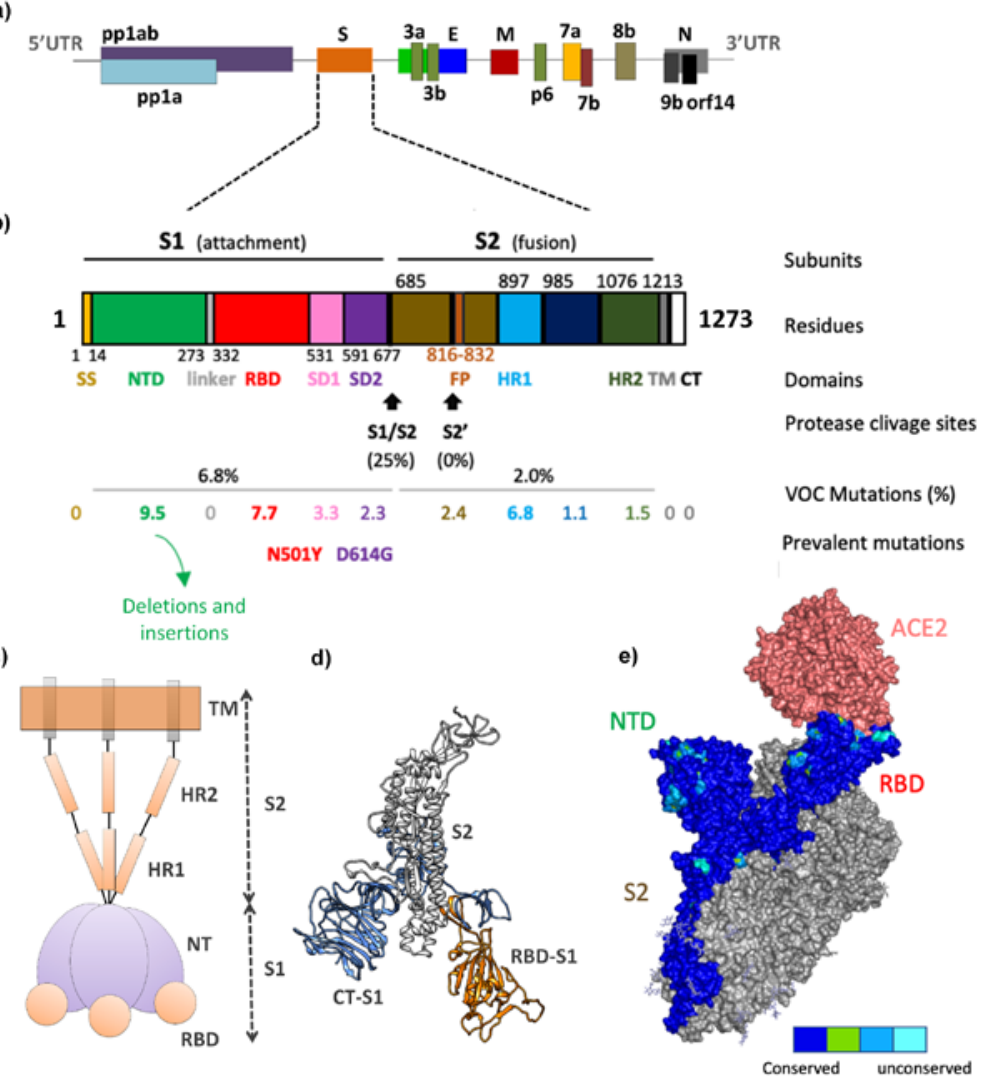

Figure 1. Structural features of SARS-CoV-2 Spike protein. a) Genomic organization of SARS-CoV-2 based on the sequence of locus NC_045512.2 in the NCBI. b) Domains in the Spike sequence. Table 2. Spike protein has two main subunits: S1 and S2, the first is related to the binding to the host cellular receptor, whereas the last allows the fusion of the viral and cellular membranes. During the infection process, the Spike protein is processed by a human serine protease, TMPRSS2, at the S1/S2 and the S2' sites to activate virus entry [10-13]. The total length of SARS-CoV-2 Spike is $\sim 1273$ amino acids and consists of a signal peptide (SP) located at the N-terminus followed by the the S1 subunit composed of: a N-terminal domain (NTD), a receptor binding domain (RBD), and SD1 and SD2 domains. The S2 subunit is composed of: the fusion peptide (FP), the heptapeptide repeat sequences 1 (HR1) and 2 (HR2), a transmembrane domain (TM), and a cytoplasm domain (CT) $[5,6]$. The percentage of mutations in each domain of the Spike protein in relation to the Alpha, Beta, Gamma, Delta and Omicron variants is shown. There are more mutations in the S1 (6.8\%) than in the S2 domain (2\%). Deletions and insertions have been observed in the NTD. Significant mutations have accumulated in the interface of interaction between the RBD Spike protein and ACE2. The S1/S2 protease cleavage site has $25 \%$ mutations, whilst no mutation was observed in the S2' site. c) Structural representation of the trimeric form of the Spike protein. d) Monomeric Spike protein structure. e) Conservation profile of the Spike protein among VOCs (Alpha, Beta, Gamma, Delta, and Omicron) was performed using ClustalW server [14] followed by the ConSurf Server [15,16] (Table S1). The absolutely conserved residues are colored in dark blue and those less conserved in cyan, as shown in the bar. The surface of the structure of the Spike ${ }^{W T}$ protein in complex with ACE2 (PDB ID 7DF4 [17]) is colored based on the conservation profile. The ACE2 structure is colored in salmon, and the chains A and C in the trimeric form of the Spike protein are colored in gray. 
Naturally, adaptive mutations occur in the $S$ protein that interact with hACE2, mediating the viral infection of the host cell $[18,19]$. Mutations in the Spike protein may improve or worsen infectivity, transmissibility and pathogenicity, compared to the wildtype SARS-CoV-2 (SARS-CoV-2 ${ }^{\text {WT }}$ ) [20]. In 2021, the main variants, denominated Alfa (B.1.1.7), Beta (B.1.351), Gamma (P.1), and Delta (B.1.617.2), spread worldwide, bringing more uncertainties about the pandemic course [21]. The Delta variant became the dominant variant (from $10 \%$ to over 90\%) in less than 2 months in the studied countries (Figure S1) [22]. In November 2021, a novel variant denominated Omicron (B.1.1.529) was reported, presenting a much higher number of mutations (26 to 32 mutations only in the Spike protein) and raising concerns regarding how it would behave [23]. Nowadays, the world is facing a new wave due to SARS-CoV-2Omicron, which is highly infectious and is becoming the dominant variant worldwide.

Turkahia and collaborators showed evidence of recombination, mainly between the SARS-CoV-2Alpha and SARS-CoV-2B.1.177 variants, and found that most recombination breakpoints were located within the gene coding for the Spike protein [24]. Another issue is the observed cases of co-infection by SARS-CoV-2 and Influenza [25,26]. RNA recombination between coronaviruses and Influenza $C$ has been reported [27], suggesting that a novel SARS-CoV-2 variant that contains genetic information from both viruses might emerge. Such possibilities make the scientific and medical communities worry about vaccine effectiveness, symptoms, disease severity, transmissibility, and even the efficiency of current diagnostic tests for SARS-CoV-2.

Molecular dynamics simulations and cryo-electron microscopy have shown that the dominant substitution D614G favors the up-conformation of the RDB of the Spike trimer [28-30], which is more accessible for interacting with hACE2 [3,6,31,32]. In the case of SARS-CoV-2 ${ }^{\text {WT }}$, only one out of three RBDs is in the up-conformation. As for SARS-CoV$2^{\text {Delta, }}$ all three RBDs are in the up-conformation state, increasing the likelihood of hACE2 interaction (Figure S2). Mutations, especially in the RBD, increase the virus capability to infect and to become more transmissible and resistant to the immune system [33-37]. Furthermore, specific mutations may alter the equilibrium dissociation constant $\left(K_{\mathrm{D}}\right)$, the association constant $\left(k_{\mathrm{a}}\right)$ and the dissociation constant $\left(k_{\mathrm{d}}\right)$, all critical properties for the interaction with hACE2 $[38,39]$. Experimental studies demonstrated that SARS-CoV-2 is evolving to resist neutralizing antibodies. It has been shown that the E484K mutation in the RBD enables viruses to evade neutralizing antibodies and this residue is one of the most variable residues among the VOCs [40] (Figures S3b, S4 and Table S1). This mutation is localized in the main antibody-recognizing region [41]. The Delta variant has been described as more transmissible than the Alpha variant [42] and presents less susceptibility to neutralizing antibodies mobilized by vaccines than other SARS-CoV-2 VOCs do [43]. Computational studies have shown that such capabilities may be caused by structural modifications as a result of L452R and T478K mutations in the RBD [44,45]. Interestingly, T478 is also a highly variable residue among the VOCs (Figure S4).

Several vaccination technologies have been developed and are being used to immunize the population worldwide. Vaccination was shown to be effective in significantly reducing the death rate for patients with COVID-19, yet not blocking the transmission of the virus, which still occurs in an apparently reduced way [46]. However, the investigation of underlying mechanisms behind emerging SARS-CoV-2 variants resistant to neutralizing antibodies induced by vaccines or previous virus infections has gained prominence in the scientific community [47]. In the present review, we approached the impacts of Spike protein mutations on infectivity and transmissibility of SARS-CoV-2 VOCs. Additionally, we discuss the capacity of the VOCs to evade neutralizing antibodies or decrease the sensitivity to antisera from convalescent and vaccinated patients, appearing to be the main factor driving the evolution of the virus [48]. We compile evidence from different studies that show the Spike protein in the SARS-CoV-2 VOCs evolved in distinct ways to present an increase of infectivity in the host cell, with higher infection fitness than the wild type. Since emergence of higher fitness VOCs is expected 
while opportunities for mutation and recombination continue to be provided by high levels of virus circulation in the hosts population, we expect continued immunization and restrictive measures to continue to be the main strategies to diminish the likelihood of VOC emergence until effective drugs that block virus infection are made available.

\section{SARS-CoV-2 VOC mutations and their impact on hACE2 binding affinity and escape from the immune system.}

The evolution of the SARS-CoV-2 Spike protein has led to key structural features that facilitate fast-spreading transmission. The D614G mutation in the Spike protein was the first that worried the scientific community during the coronavirus disease 2019 (COVID19) pandemic and is still present in all SARS-CoV-2 VOCs. This SARS-CoV-2 mutation affects viral replication in lung cells and viral infectivity. The D614G substitution does not alter Spike biosynthesis, processing, or cell-cell fusion of SARS-CoV-2, but it disrupts an interprotomer contact breaking a salt bridge between D614 and K854 located at the FPPR (Fusion peptideproximal region). Thus favoring an RBD up-conformation state to bind to hACE2 but doesn't increase protein stability [49][32]. Molecular dynamics simulations showed that conformational changes in the D614G Spike are energetically favorable for increasing infectivity due to an enhanced exposure of the RBD to interact with hACE2 [28]. This favorable structural conformation may be explained due to a displacement of the loop composed of residues 620 to 640 [49]. This substitution also promotes an increase in the number of functional Spikes [50]. Furthermore, the D614G mutation moderately increased binding affinity to hACE2, providing a clear selective advantage to these mutants compared with ancestral SARS-CoV-2 (Table 1) [49].

Table 1. Kinetic parameters of RBD-hACE2 complex formation. Equilibrium dissociation constants $\left(K_{D}\right)$ calculated for RBD and its variants in the complex with dimeric hACE2 protein. Experimental $K_{D}$ values were also measured using a trimeric Spike protein and its variants for interacting with hACE2.

\begin{tabular}{|c|c|c|c|c|c|c|}
\hline \multirow[b]{2}{*}{ Strains } & \multicolumn{3}{|c|}{ Spike Trimeric } & \multicolumn{3}{|c|}{ Spike RBD } \\
\hline & $\begin{array}{c}k_{\mathrm{a}} \\
\left(10^{5} M^{-1} S^{-1}\right)\end{array}$ & $\begin{array}{c}k_{\mathrm{d}} \\
\left(10^{-4} \mathrm{~s}^{-1}\right)\end{array}$ & $\begin{array}{c}K_{\mathrm{D}} \\
(n M)\end{array}$ & $\begin{array}{c}k_{\mathrm{a}} \\
\left(10^{5} \mathrm{M}^{-1} \mathrm{~S}^{-1}\right) \\
\end{array}$ & $\begin{array}{c}k_{\mathrm{d}} \\
\left(10^{-4} \mathrm{~s}^{-1}\right) \\
\end{array}$ & $\begin{array}{c}K_{\mathrm{D}}^{\mathrm{RBD}} \\
(n M) \\
\end{array}$ \\
\hline SARS-CoVWT & $1.4[6]$ & $7.1[6]$ & $5.0[6]$ & $1.4-15.8[51]$ & $93-338[51]$ & $1.46-185$ [51-53] \\
\hline$S A R S-C o V-2^{W T}$ & $1.4[6]$ & $1.6[6]$ & $1.2[6]$ & $9.0[54]$ & $91.6[54]$ & $1.1-112.1[45,52,53,55-59]$ \\
\hline$S A R S-C o V-2^{D 614 G}$ & $1.6[60]$ & $1.7[60]$ & $1.0[60]$ & ND & ND & $0.38-12.8[61]$ \\
\hline SARS-CoV-2Alpha & $0.1[54]$ & $1.7[54]$ & $1.6[54]$ & $13.0[54]$ & $15.5[54]$ & $0.5-57.1[45,54,56-59,61]$ \\
\hline SARS-CoV-2 ${ }^{\text {Beta }}$ & $0.3[54]$ & $3.0[54]$ & $1.1[54]$ & $12.0[54]$ & $39.4[54]$ & $3.3-25.5[45,54,56,61]$ \\
\hline SARS-CoV-2 $2^{\text {Gamma }}$ & $0.2[54]$ & $3.0[54]$ & $1.8[54]$ & $13.0[54]$ & $28.8[54]$ & $2.2[54]$ \\
\hline SARS-CoV-2 Delta & ND & ND & ND & $0.1[62]$ & $46.0[62]$ & $2.7-176[22,62]$ \\
\hline
\end{tabular}

$\mathrm{ND}=$ not determined, $K_{\mathrm{D}}=k_{\mathrm{d}} / k_{\mathrm{a}}$.

The main SARS-CoV-2 VOCs are Alpha, Beta, Gamma, Delta and Omicron, in which the main mutations are localized in the Spike protein. In the Spike S1 subunit, the main changes happen in the NTD and RBD domains, while in the S2 subunit it happens in the HR1 domain (Figure 1B). Analysis of residue variability along the VOCs shows that Y145, K417, T478, E484 and H655 are very variable and most of them are exposed or involved in the hACE interaction (Figures 1e and S4). This suggests that they may be important for evading the immune system or for modulating human receptor binding. The NTD and RBD are the main targets of neutralizing antibodies and the elevated number of mutations observed in these domains for novel SARS-CoV-2 VOCs suggests that the virus might be evolving to escape the neutralizing action of antibodies produced by immunization or earlier infections. Figure S3 shows the multiple sequence alignment of Spike protein variants from SARS-CoV-2 VOCs. The Alpha variant, first detected in the United Kingdom, has mutations $\Delta 69-70, \Delta 144$, N501Y, A570D, D614G, P681H, T716I, S982A and 
D1118H. The Beta (B.1.351) variant, first reported in South Africa, presents L18F, D80A, D215G, $4242-244$, R246I, K417N, N501Y, D614G and A701V mutations. The Gamma (P.1) variant, first identified in Brazil, presents mutations L18F, T20N, P26S, D138Y, R190S, K417T, E484K, N501Y, D614G, H655Y, T1027I and V1176F. The Delta (B.1.617.2) variant, first identified in India, has mutations T19R, $157-158$, L452R, T478K, D614G, P681R and D950N in the Spike protein. Finally, the Omicron (B.1.1.529) variant, first reported also in South Africa, has mutations in A67V, $469-70$, T95I, $4142-144$, Y145D, $\Delta 211$, L212I, insertion of EPE at position 214, G339D, S371L, S373P, S375F, K417N, N440K, G446S, S477N, T478K, E484A, Q493R, G496S, Q498R, N501Y, Y505H, T547K, D614G, H655Y, N679K, P681H, N764K, D796Y, N856K, Q954H, N969K and L981F [63].

Mutations in the Spike protein correlate to enhanced virus fitness (such as the prevalent mutations, N501Y and D614G), increased binding to the hACE2 (such as N501Y), and resistance against neutralizing antibodies (highly variable residues among VOCs, such as T478 and E484). All these mutations cause conformational changes of the Spike trimer structure. Indeed, cryo-EM structures of the Alpha variant spike protein reveal a rotation of all three S1 subunits leading to up-conformation of the RBD [61]. When compared with D614G, the SARS-CoV-2 ${ }^{\text {Beta }}$ Spike presents a similar conformational state, differing only in the NTD of the Spike S1 subunit [61]. The triple-residue deletions (L242, L243 and A244) in the SARS-CoV-2 ${ }^{\text {Beta }}$ Spike protein result in structural changes in the adjacent loop (residues 246 to 260) and the nearby loop (residues 144 to 155), both of which form part of neutralizing epitopes [61]. These structural changes may affect the binding of neutralizing antibodies [61] and likely affect the efficiency of currently used COVID-19 vaccines. The cryo-EM structure reveals that RBDs of SARS-CoV-2Gamma Spike protein mainly visit the up conformation [64]. The change in L452R in the Spike protein of SARSCoV-2Delta may contribute to $50 \%$ more transmissibility than the Alpha variant [65]. It could be correlated with electrostatic interactions with hACE2 [44,45].

Each SARS-CoV-2 VOC presents different values of $k_{\mathrm{a}}, k_{\mathrm{d}}$ and $K_{\mathrm{D}}$ for the interaction between the RBD or the trimeric form of the Spike protein and hACE2 (Table 1). Veesler and co-authors performed binding affinity assays to hACE2, comparing the trimeric Spike from SARS-CoV-2 variant with SARS-CoV-2 ${ }^{\text {WT }}$, showing a ratio $K_{D}{ }^{\text {VARIANT }} / K_{D}{ }^{W T}$ of $~ 1: 5$ [6]. When compared to SARS-CoV, SARS-CoV-2 Spike $k_{a}$ kept the same value of $\sim 1.4 \times 10^{5}$ $\mathrm{M}^{-1} \mathrm{~s}^{-1}$ but decreased its $k_{\mathrm{d}}$ value from $3.0 \times 10^{-4} \mathrm{~s}^{-1}$ to $\sim 1.7 \times 10^{-4} \mathrm{~s}^{-1}$. In relation to the Spike of SARS-CoV-2 ${ }^{\mathrm{WT}}$, D614G Spike trimer presents comparable $k_{\mathrm{a}}$ and $k_{\mathrm{d}}$ rates of $\sim 1.6 \times 10^{5} \mathrm{M}^{-1} \cdot \mathrm{s}^{-1}$ and $\sim 1.7 \times 10^{-4} \mathrm{~s}^{-1}$, resulting in similar binding affinity to hACE2 $\left(K_{D}{ }^{\text {SARS-CoV- } 2} / K_{D}{ }^{D 614 G}\right.$ of $\left.\sim 1: 1\right)$ [60].

Our previous studies have shown that the Spike protein of SARS-CoV-2Alpha, SARSCoV-2 ${ }^{\text {Beta }}$ and SARS-CoV-2 ${ }^{\text {Gamma }}$ present comparable values of binding affinity to hACE as SARS-CoV-2 ${ }^{\mathrm{WT}}$, with $K_{\mathrm{D}}$ values ranging from 1.1 to $1.8 \mathrm{nM}$ [54], but higher affinity than the trimeric form of the Spike protein of SARS-CoV-2 ${ }^{\mathrm{WT}}\left(K_{\mathrm{D}}\right.$ values $\left.\sim 16 \mathrm{nM}\right)$ [55]. A similar results was also observed for the Omicron variant that has higher affinity to hACE than the wild type but comparable values of binding affinity to hACE as SARS-CoV-2Beta [66].The main significant differences seem to be in the $k_{\mathrm{a}}$ and $k_{\mathrm{d}}$ values, ranging $0.1-0.3 \times 10^{5}$

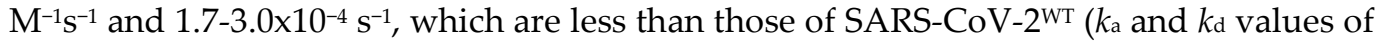
$0.4 \times 10^{5} \mathrm{M}^{-1} \mathrm{~s}^{-1}$ and $7.0 \times 10^{-4} \mathrm{~s}^{-1}$, respectively) [55]. Lower differences in the $K_{\mathrm{D}}$ values, but larger ones in $k_{\mathrm{a}}$ and $k_{\mathrm{d}}$ values, imply changes to the binding kinetics to hACE2. Decreasing $k_{\mathrm{d}}$ values due to mutations in these SARS-CoV-2 variants increase the likelihood of Spike protein will be cleaved by proteases, vital to membrane fusion and virus cell host entry. Therefore, these variants seem to improve virus entry in the host cell by increasing the probability of cleavage of the Spike protein by proteases, a step that is a requirement for the process of membrane fusion [55].

The emergence of novel SARS-CoV-2 VOCs with significant mutations in the Spike protein might result in changes of the virus tropism. This can occur when the proteases cleavage sites are mutated, as already observed for the Alpha, Delta, and Omicron variants (Figure S3b), or if the Spike protein starts to recognize other human receptors, 
expanding the repertoire of entry points of the virus to new human cell lineages. This would result in different clinical symptoms of the disease and a significant decrease of efficiency of previous immune responses, acquired by previous infections or immunization based on SARS-CoV-2 ${ }^{\text {WT }}$. This observation has been reported for the Omicron variant, which replicates faster in the airways and has an increased fitness compared to the D614G and Delta variants [67]. The replication of the Omicron variant in alveolar type 2 cells is not productive and does not efficiently use TMPRSS2 for entry or spread through cell-cell fusion [67]. Omicron has an altered protease usage and tropism, as shown in animal model studies, features that are probably related to this variant's decreased pathogenicity compared to previous variants [67].

\section{SARS-CoV-2 VOC decreases incubation period, increasing viral loads, transmission period, and transmissivity.}

One of the factors that contributed to SARS-CoV-2 becoming a pandemic virus is that viral transmission occurs in asymptomatic infected individuals and before the appearance of symptoms in symptomatic cases. The kinetics of SARS-CoV-2 infection involve contact with the virus, viral incubation, period of viral transmission (viral shedding) that is associated with increased viral load in the infected person, the period of symptom onset, and detection of viral RNA (viral RNA shedding) by diagnostic tests (Figure 2) [68,69]. The degree of viral transmissibility can be measured by the number of people who are infected for each person previously infected when everyone is susceptible. This number is called effective reproduction number $\mathrm{R}_{0}$ [70]. In general, the highest viral loads are reached when symptoms appear, gradually declining until vanishing around 21 days after the onset of symptoms. However, the live virus is only detectable up to the eighth day after the onset of symptoms [71], which may decrease transmissibility after this period. Viral loads are similar across age, sex and disease severity [72]. Interestingly, men transmit SARS-CoV-2 more effectively than women do [73]. This may be explained by the observation that men, aged 48 or less, have a viral load about ten times higher in the saliva than women [73]. Nevertheless, no differences were observed, in this cohort, for samples of nasofaringe, thus suggesting such biases may not apply to variants with different tropism.

Considering the SARS-CoV epidemic context, estimated $R_{0}$ values ranged from $\sim 0.5$ to 1.3 [74]. Conversely, COVID-19 pandemic showed a compelling increase of $R_{0}$ values, ranging from 1.4 to 3.9 [75] (Table 2). In general, SARS-CoV-2 VOCs tend to have higher $R_{0}$ values relative to the wild-type SARS-CoV-2. In particular, the substitution D614G in the Spike protein makes SARS-CoV-2 31\% more transmissible ( $R_{0}$ value ranging from 1.7 to 4.7) [76]. Shi and co-authors showed that hamsters infected with SARS-CoV-2 expressing D614G Spike mutant may also reveal increased virus transmission [77]. Increases in severity and mortality of COVID-19 are not associated with this D614G mutation [20], since the Alpha, Beta, and Delta variants all share this substitution. The higher transmissibility associated with this mutation seems to derive from an increase in viral load in younger patients [20]. The Alpha variant, whose estimated $R_{0}$ interval is from 2.2 to 6.1 (Table 2), is from 43 to $90 \%$ more transmissible than SARS-CoV-2 ${ }^{\mathrm{WT}}$ [78]. The Beta variant is $\sim 50 \%$ more transmissible than the SARS-CoV-2 ${ }^{\text {WT }}$ [79] and it is estimated to have an $R_{0}$ ranging from 2.1 to 5.5 (Table 2). The Gamma variant is $\sim 40-120 \%$ more transmissible than SARS-CoV-2 ${ }^{\text {WT }}$ [80], which corresponds to an estimated $R_{0}$ ranging from 2.1 to 5.5 (Table 2). The Gamma variant evades neutralizing antibodies, leading to possibly higher rates of SARS-CoV-2 reinfection [81], and the same might happen to the other SARS-CoV-2 VOCs. The Ro of the Omicron variant is estimated to be as high as 10 . As a result, the control of viral transmission in the UK is almost impossible since the cases of Omicron are doubling every 2-3 days [82], testing has been suggested to help to control the virus spreading [82].

SARS-CoV-2 VOCs modulate the kinetics of SARS-CoV-2 infection in a way that improves the virus fitness in the human body (Figure 2), thus leading to reduced vaccine 
effectiveness and, in some cases, to increase disease severity. Concerning the Delta variant, which became the dominant lineage worldwide in 2021, the transmissibility rate (Ro) increased from 1-4 to 6.4 [70,83], driven by higher viral loads (PCR Ct values) [68,84], shorter time to peak viral load (shorter incubation period [70,83]), longer viral shedding (slower decline), and abrogated neutralization capacity compared to non-Delta SARSCoV-2 variants [43] (Table 2). Interestingly, the Delta variant is associated with higher odds of oxygen requirement, intensive care unit admission, or death [68]. One of the explanations for the fast spreading of the Delta variant is its higher viral replication rate (2.7) [85] (Table 2), which results in higher viral loads and shorter incubation time. Nonetheless, in regard to the Delta variant, the symptoms onset is about 5.8 days after infection, not very different from wild-type SARS-CoV-2 [72,86] (Table 2). As a consequence, there is an increasing period of time in which infected people are spreading the virus in the presymptomatic stage. Subjects infected with the Delta variant may commence transmission 1.8 days prior to symptoms onset, compared to 0.8 days for previously SARS-CoV-2 variants. Consequently, it was estimated that $44 \%$ of the secondary cases were infected by presymptomatic people, and this number may have raised up to $74 \%$ for the Delta variant $[72,86]$. Since December of 2021, the Omicron variant was found to spread even faster than the Delta variant mainly due to its ability to escape the immune response, even as this variant is seemingly less lethal than previous ones. The Omicron variant has become the most prevalent variant in the beginning of 2022 worldwide.
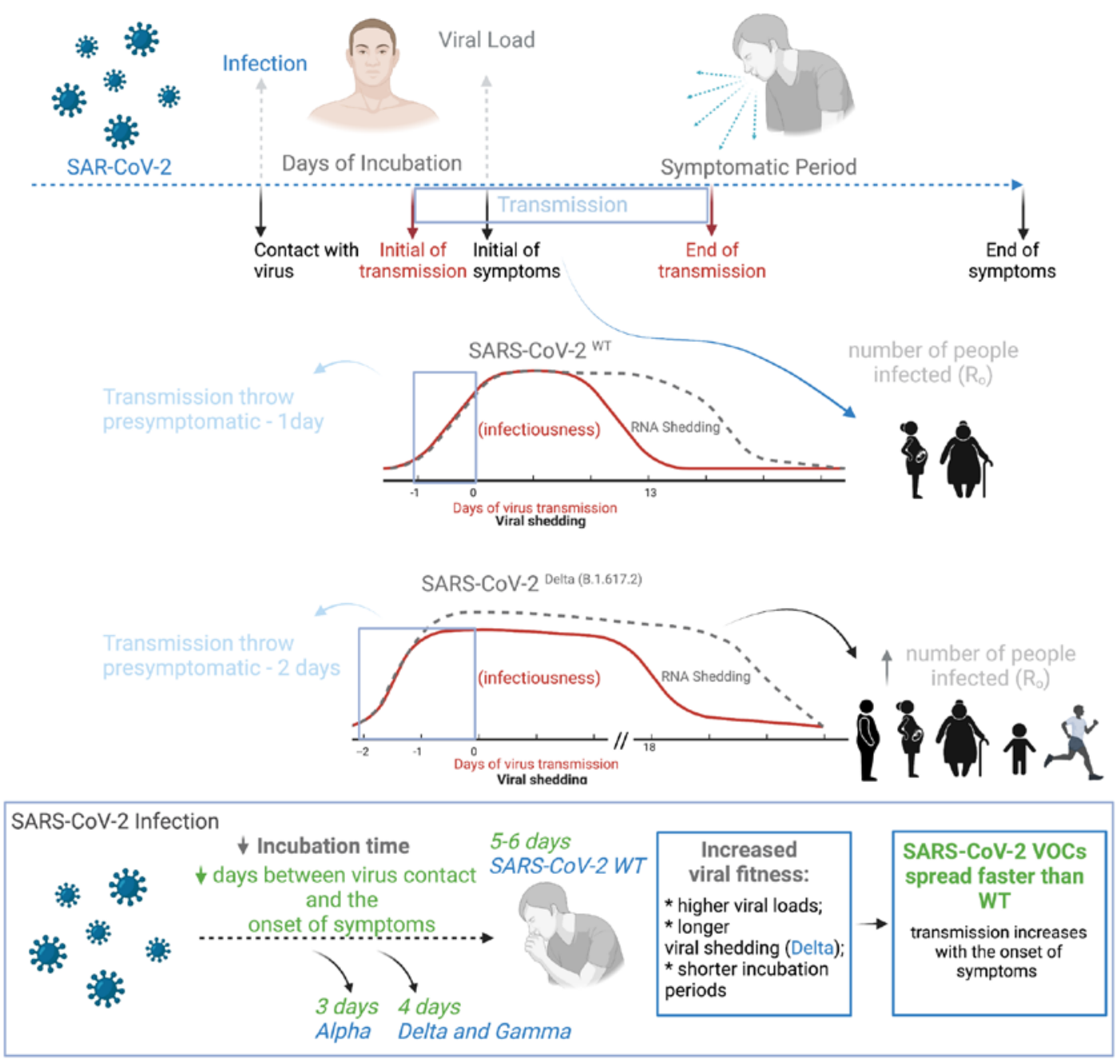

Figure 2. The kinetics of SARS-CoV-2 infection. The SARS-CoV-2 infection involves contact with Table 2. 
Table 2. Biological features of SARS-CoV, SARS-CoV-2 and SARS-CoV-2 variants. The median incubation period for the Alpha variant has been estimated at around 3 days, compared to around 5 days for ancestral strains [87-89]. The Delta variant has a shorter incubation period when compared to ancestral strains (4 days vs. 6 days) $[89,90]$.

\begin{tabular}{|c|c|c|c|c|c|c|c|c|}
\hline Strains & $\begin{array}{c}\text { Spike density } \\
\text { (unit/virion) }\end{array}$ & $\begin{array}{c}\text { Mean S1/S2 } \\
\text { ratio }^{\&}\end{array}$ & $\begin{array}{l}\text { Viral Load } \\
\left(\text { mean } C_{T}\right)^{\#}\end{array}$ & $\begin{array}{c}\text { Initial } \\
\text { Viral Load } \\
\left(\text { mean } C_{T}\right)^{*}\end{array}$ & $\begin{array}{c}\text { Days of } \\
\text { virus } \\
\text { incubation }\end{array}$ & $\begin{array}{l}\text { Days of } \\
\text { viral } \\
\text { shedding }\end{array}$ & $R_{0}$ & $\begin{array}{l}\text { Growth } \\
\text { rate, } \log _{10} \\
\text { units per } \\
\text { day }\end{array}$ \\
\hline SARS-CoV & $50-100[91]$ & $1.1[92]$ & 26.9 [93] & ND & ND & ND & $0.54-1.3[74]$ & ND \\
\hline SARS-CoV-2WT & $11-41[94]$ & $1.0[95]$ & $21.2[96]$ & $28[68]$ & $5-7[90,97]$ & $13[90]$ & $1.4-3.9$ [75] & $3.2[85]$ \\
\hline SARS-CoV-2 D614G & $28-103$ [97] & 1.0 [95] & 19.9 [96] & ND & ND & $13[90]$ & $1.7-4.7[76]$ & ND \\
\hline SARS-CoV-2 $2^{\text {Alpha }}$ & 28-103 [97] & 1.2 [95] & $17.4[98]$ & $22[68]$ & $3[90]$ & $13[90]$ & $2.2-6.1[78]$ & 3.1 [85] \\
\hline SARS-CoV-2 Beta & $28-103$ [97] & $1.2[95]$ & 18.9 [99] & 22 [68] & ND & $13[90]$ & $2.1-5.5[79]$ & ND \\
\hline SARS-CoV-2 ${ }^{\text {Gamma }}$ & $28-103$ [97] & 1.2 [95] & $19.8[100]$ & ND & ND & ND & $4.7-4.9[80]$ & ND \\
\hline SARS-CoV-2 Delta & ND & ND & ND & 18 [68] & $4-6[86,90]$ & $18[90]$ & $5.0-8.0$ [89] & $2.7[85]$ \\
\hline
\end{tabular}

\& increased S-protein density in the virion as well as the increase of S1/S2 ratio correlate with this increased infectivity due to mutation D614G. D614G increases the stability of the Spike protein, decreasing the natural loss of S1 subunit, thus enhancing functional Spikes into the virion. D614G does not affect affinity to hACE2 [50,95]. * Viral load is determined using RT-PCR from nasal swab samples. * PCR Serial cycle threshold values in the beginning of the COVID-19 symptoms. ** Mean number of days after COVID-19 initial symptoms for the patient to decrease the viral load (PCR Cт (mean) bigger than 30). ND $=$ not determined

\section{SARS-CoV-2 VOCs present less sensitivity to neutralizing antibodies than ancestral SARS-CoV-2}

Currently, more than 180 anti-SARS-CoV-2 vaccine candidates are in clinical trials. These candidates include inactivated, live attenuated, recombinant protein, vectored, RNA-based and DNA-based vaccines [101].

Inactivated vaccines. Inactivated vaccines are developed by growing viruses in cell culture followed by chemical or heat inactivation. Inactivated vaccines include CoronaVac, which are administered intramuscularly with adjuvants [102]. In Brazil, CoronaVac has shown, after two doses, 51\% efficacy against symptomatic cases and $100 \%$ against hospitalization and mortality caused by COVID-19 [103]. A phase 3 trial in Turkey has shown an efficacy of $86.3 \%$ against the Alpha variant and $96.4 \%$ against non-Alpha variants [104]. CoronaVac was shown to be tolerable and to present immunogenicity and safety in children and adolescents from 3 to 17 years and healthy adults aged from 18 to 59 years $[105,106]$. Covaxin (BBV152) is also an inactivated virus vaccine, which stimulates a protective immune response and, in phase 3 trial data, has an efficacy of $77.8 \%$ [107]. It was demonstrated that neutralization activities of sera from vaccinated people with BBV152 presented the same efficacy for the Alpha variant [108]. However, neutralization activity of sera collected from convalescent patients and vaccinated individuals with two doses of BBV152 demonstrated a decrease in neutralization titers against Beta and Delta [109]. Notwithstanding, these sera still showed a protective response against these variants [109]. BBV152 presented $65.2 \%$ protection against the Delta variant in Phase 3 clinical trial [107].

Live attenuated vaccines $\mathcal{E}$ recombinant protein vaccines. Live attenuated vaccines are produced by a genetically weakened virus version, which induces an immune response similar to that occurring upon natural infection. Recombinant protein vaccines involve the use of recombinant Spike protein. An example for that is Spike injection, such as in the case of the Novavax vaccine [110]. The Novavax (NVX-CoV2373 or Covovax) was developed by Novavax and the Coalition for Epidemic Preparedness Innovations (CEPI). In a randomized study, after two doses of the NVX-CoV2373, the vaccine protected $89.7 \%$ against SARS-CoV-2 infection and showed $86.3 \%$ efficacy against the Alpha variant [110].

Replication-incompetent vectors. Replication-incompetent vectors are based on another virus that presents partial deletions of its genome and is able to express the Spike protein. These vaccines use vectors, for example, adenovirus, human parainfluenza virus, and 
influenza virus. An adenovirus-based vaccine, Gam-COVID-Vac (Sputnik V), showed good safety and has shown to induce immune responses in participants aged 18 years or older [111]. The vaccine was administered in two doses intramuscularly during 21 days using two different recombinant adenovirus vectors (rAd26 and rAd5), both of them presenting the gene for the full-length SARS-CoV-2 Spike protein [111]. The Gam-COVIDVac showed good efficacy (91.6\%) and was tolerable in most participants [111]. OxfordAstraZeneca vaccine (AZD1222) is recommended for people aged 18 years or older. A randomized study performed in Brazil, South Africa, and the United Kingdom revealed an efficacy of $70.4 \%$ after participants have received two doses (each dose containing $5 \times 10^{10}$ viral particles) [112]. The vaccine of Janssen Pharmaceuticals Companies of Johnson \& Johnson (JNJ-78436735) is also recommended for people of 18 years or older and had an efficacy of $63.3 \%$ in a clinical trial with people who had received only one dose [113].

RNA-based vaccines. RNA-based vaccines are recent developments and, similar to DNA-based vaccines, use the genetic information to produce the antigen in the cells. Currently, mRNA-based vaccines produce recombinant Spike protein and are developed by Moderna and Pfizer-BioNTech. Moderna COVID-19 Vaccine (mRNA-1273) is recommended for people aged 18 years or older and presented an efficacy of $94.1 \%$ after two doses [114]. Specifically, vaccine effectiveness against the Alpha variant was 88.1 and $100 \%$ after the first and second doses, respectively [115]. However, the effectiveness against Beta was 61.3 and $96.4 \%$ after first and second doses, respectively [115]. The PfizerBioNTech vaccine (BNT162b2) is recommended for people 12 years or older [116]. In addition, the Pfizer-BioNTech vaccine is approved for individuals who are 5 years of age or older. However, in the present data, safety and effectiveness of this vaccine in children younger than 5 years have not yet been established [117]. Similarly, the Pfizer-BioNTech vaccine efficacy was 95\%, protecting against SARS-CoV-2 in people who received two doses [116]. Notably, low efficacy was found after only 1 dose of BNT162b2 and AZD1222 vaccine, presenting $\sim 34 \%$ against Delta and $~ 51 \%$ against Alpha [118]. After the second dose of BNT162b2, on the other hand, efficacy was $93.4 \%$ for Alpha and $87.9 \%$ for Delta variants. Likewise, AZD1222 presented an efficacy of $66.1 \%$ for Alpha and $59.8 \%$ for Delta variants [118].

Virus evolution in order to evade the immune system and to survive. The emergence of novel SARS-CoV-2 variants is expected, though the selection of variants that circumvent the neutralizing effect of plasma from convalescent and immunized patients is under concern [119]. The course of the virus evolution in order to survive involves evading the immune system and infecting more and more people, spreading further and increasing its population. This hypothesis has been related to the decreasing sensitivity to neutralizing antibodies from infected patients with SARS-CoV-2, exerting a selective pressure, with a major concern of emerging resistant SARS-CoV-2 variants [120].

Nussenzweig and co-authors showed that convalescent plasma samples had less than 50 titres in 33\% of infected individuals, more than 1,000 in 79\%, and more than 5,000 in $1 \%$, demonstrating that most convalescent plasma samples did not have high levels of neutralizing antibodies [121]. The sensitivity of neutralizing antibodies produced by convalescent patients or induced by vaccines is higher in SARS-CoV-2 ${ }^{\mathrm{WT}}$ and, in general, the performance of this sensitivity is decreased against any SARS-CoV-2 VOCs (Table 3). According to Tables 3 and 4, the Beta SARS-CoV-2 variant, in relation to the Alpha variant and the wild type, is more resistant to convalescent patient antisera and vaccine-induced antibodies. Indeed, sera from convalescent patients after 12 months of SARS-CoV-2 infection show that neutralizing antibodies is 4-fold less sensitive against Delta than Alpha [43]. Furthermore, only a single dose of vaccines, either AstraZeneca or Pfizer, did not protect against Delta infection, while two doses generated efficient immune responses against this variant [43]. These data suggest that SARS-CoV-2 variants that elicit a less effective immune response or that are more resistant against neutralizing antibodies are more successful and become the source of worldwide fast spreading waves of virus infections, thus extending the duration of the pandemic. 
Table 3. Sensitivity of sera from Convalescent patients and individuals vaccinated with Moderna, Pfizer-BioNTech and Oxford-AstraZeneca vaccines. The sensitivity of neutralizing antibodies produced by convalescent patients or induced by vaccines is higher in ancestral SARS-CoV-2 and, in general, the performance of this sensitivity is worse against any SARSCoV-2 variants.

\begin{tabular}{|c|c|c|c|c|}
\hline Strains & $\begin{array}{c}\text { Convalescent patient } \\
\left(I D_{50}\right)\end{array}$ & Moderna $\left(I C_{50} / I D_{50}\right)$ & $\begin{array}{c}\text { Pfizer-BioNTech } \\
\left(I_{50} / \text { FRNT }_{50}\right)\end{array}$ & $\begin{array}{c}\text { Oxford-AstraZeneca } \\
\left.\text { (FRNT } T_{50}\right)\end{array}$ \\
\hline SARS-CoVWT & $1,500-8,000[122]$ & $\mathrm{ND} / \mathrm{ND}$ & $\mathrm{ND} / \mathrm{ND}$ & ND \\
\hline SARS-CoV-2 $2^{W T}$ & $1,402[95]$ & $\mathrm{ND} / 3,067$ [95] & $\mathrm{ND} / 1,105$ [123] & $306[123]$ \\
\hline SARS-CoV-2 D614G & $1,485[95]$ & 833 [124]/2,906 [95] & $695[124] / \mathrm{ND}$ & ND \\
\hline SARS-CoV-2Alpha & $1,290[95]$ & 722 [124]/1,578 [95] & $626[124] / 337$ [123] & $131[123]$ \\
\hline SARS-CoV-2 ${ }^{\text {Beta }}$ & 309 [95] & $182[124] / 477[95]$ & 114 [124]/146 [123] & 34 [123] \\
\hline
\end{tabular}

$\mathrm{ND}=$ not determined. $\mathrm{IC}_{50}$ and $\mathrm{ID}_{50}=$ titers in serum for neutralizing 50\% SARS-CoV-2 in vitro. $\mathrm{FRNT}_{50}=$ focus reduction neutralization test $50(\mu \mathrm{g} / \mathrm{mL})$; titers in serum for neutralizing $50 \%$ SARS-CoV-2 in vitro.

Table 4. Sensitivity of sera induced by Sputnik V, Janssen, CoronaVac and Covaxin vaccines. The sensitivity of neutralizing antibodies induced by vaccines is superior in ancestral SARS-CoV-2 and, in general, the performance of this sensitivity is reduced against any SARS-CoV-2 variants.

\begin{tabular}{|c|c|c|c|c|}
\hline Strains & $\begin{array}{c}\text { Sputnik V } \\
\text { IC } C_{50}\end{array}$ & $\begin{array}{c}\text { Janssen } \\
\text { IC }_{50}\end{array}$ & $\begin{array}{c}\text { CoronaVac } \\
\text { ID }_{50}\end{array}$ & $\begin{array}{l}\text { Covaxin } \\
\text { PRNT50 }_{5}\end{array}$ \\
\hline SARS-CoVWT & ND & ND & ND & ND \\
\hline SARS-CoV-2 WT & ND & ND & 774.48 [125] & ND \\
\hline SARS-CoV-2 ${ }^{D 614 G}$ & 49.4 [126] & $221[124] / 246$ [127] & ND & ND \\
\hline SARS-CoV-2Alpha & 87.1 [126] & $232[124] / 266$ [127] & $44.64[125]$ & ND \\
\hline SARS-CoV-2 ${ }^{\text {Beta }}$ & $7.9[126]$ & 33 [124]/68 [127] & $35.03[125]$ & 61.6 [128] \\
\hline SARS-CoV-2 Gamma & ND & $72[127]$ & ND & ND \\
\hline SARS-Cov-2 $2^{\text {Delta }}$ & ND & $30[124] / 154[127]$ & $24.5[125]$ & 69 [128] \\
\hline
\end{tabular}

$\mathrm{ND}=$ not determined. $\mathrm{IC}_{50}$ and $\mathrm{ID}_{50}=$ titers in serum for neutralizing $50 \%$ SARS-CoV-2 in vitro. PRNT50 = Plaque reduction neutralization test. Titers in serum for neutralizing 50\% SARS-CoV-2 in vitro.

When compared to sera from convalescent patients infected with SARS-CoV, antisera from SARS-CoV-2 infected convalescent patients presented a significant loss of sensitivity to virus (ID $50^{\text {SARS-CoV }}$ range from 1,500 to 8,000 , while ID $50^{\text {SARS-CoV-2 }}$ has value of 1,402 ) (Table 3). Evidently, the sensitivity to neutralizing antibodies obtained from convalescent patients and vaccinated patients (mRNA-1273, Moderna) showed similar profiles in SARS-CoV-2WT and D614G variant (Table 3-4). Sensibility reduction was observed in neutralization of Kappa (B.1.617.1) and Delta (B.1.617.2) by antisera obtained from convalescent patients and vaccinated individuals. A loss of protection efficacy of 3.9-fold for convalescent plasma, 2.7-fold for the Pfizer-BioNTech vaccine, and 2.6-fold for the Oxford-AstraZeneca vaccine was observed for the Kappa variant. For infection by Delta, protection rates decline 2.7-, 2.5-, and 4.3-fold, respectively. Such reduced efficacies were comparable in scale with those seen for Alpha and Gamma, with no evidence of widespread escape from neutralization, in contrast to that observed for Beta. These results make it likely that the current RNA and viral vector vaccines will provide protection against the B.1.617 lineage, although an increase in breakthrough infections may occur as a result of the reduced neutralizing capacity of sera. Unfortunately, after two doses of CoronaVac, neutralizing antibodies seem to be less effective against any SARS-CoV-2 variants, mainly the Delta variant (Table 4). In the case of the Omicron variant, convalescent patients or immunized patients with Ad26.COV2.S (single dose), BBIBPCorV or Sputnik V had no neutralizing activity against Omicron with exception for one Ad26.COV2.S and three BBIBP-CorV immunized patients serum. Serum of immunized individuals with mRNA1273, BNT162b2, and AZD1222 displayed higher neutralization against Wuhan-Hu-1 and activity against Omicron with a decrease of 33-, 44- and 36-fold, respectively. Interestingly, serum from vaccinated cohorts who were previously infected displayed higher neutralizing antibodies with a decrease of 5-fold [66]. Therefore, the 
SARS-CoV-2 population seems to be evolving towards strains that are less affected by neutralizing antibodies induced by vaccines or previous SARS-CoV-2 infection.

It is worth mentioning that antibody-dependent enhancement (ADE) is an alternative mechanism that some viruses use to infect cells [129-131]. This happens when the virus binds to receptor molecules, known as $\mathrm{Fc} \gamma$ receptors (Fc $\gamma \mathrm{Rs}$ ), on immune cells such as macrophages or monocytes and uses these receptors as a route to internalize the virus. Antibodies to any viral epitope with low affinity or in sub-optimal titer can induce ADE [132]. In the case of infection by SARS-CoV-2, the antibodies produced may elicit ADE following infection [133,134] primarily by the interaction with two types of Fc $\gamma$ Rs, Fc $\gamma$ RIIA and Fc $\gamma$ RIIIA. Nevertheless, no virus replication in macrophage cells was observed [133-135]. This mechanism seems to not be correlated to aberrant cytokine release by macrophages during some cases of SARS-CoV-2 infection, still it may function as a mechanism to trap the virus in the macrophages [133].

\section{SARS-CoV-2 VOC Spike protein evolved different ways to facilitate virus spreading and evasion of neutralizing antibodies}

The Spike surface protein of main SARS-CoV-2 VOCs have evolved to increase viral fitness and facilitate the virus spreading (Figure 2). For this, at least six different mechanisms have been described that increase the efficiency of infection by SARS-CoV-2 VOCs and are directly related to mutations in the Spike protein (Figure 3): (1) increasing hACE2 affinity $\left(K_{\mathrm{D}}\right)$; and (2) extending the time the Spike protein remains bound to hACE2, thus increasing the likelihood that Spike is cleaved by proteases and proceeds to membrane fusion. (3) The Spike D614G mutation favors the up conformation of the RBD in the trimeric state of the protein, amplifying the amount of Spike protein subunits able to bind to hACE2. This mutation also (4) better stabilizes the trimeric form of the Spike protein (its unclived form). The Spike protein may spontaneously shed its S1 subunit and this early cleavage leads to protein inactivation, preventing virus infection. The Spike D614G mutation boosts the amount of Spike proteins in the surface of the virion able to bind the human receptor and, as a result, increases the infectivity rate. (5) Mutations in L452R, T478K and E484K located at the RBD increase the resistance to neutralizing antibodies. Therefore, it is a mechanism to evade the immune response and an alert to possible new mutations in Spike that could impair the effectiveness of current vaccines. Finally, (6) the Spike D614G mutation also raises the number of Spike proteins per viral particle. This observation implies a shift in the chemical equilibrium Spike + hACE2 $\rightleftharpoons$ Spike-hACE2 is expected and an increase in Spike protein numbers per viral particle should be enough to increase the effectiveness of viral infection, as it elevates the amount of Spike bound to hACE2. Interestingly, this phenomenon could cause the virus to bind to tissues with a low amount of hACE2, which could change the severity and pathology of the disease. It may also result in a decrease of the viral dose required to cause infection. Taken together, all mechanisms described above end up helping Spike's access to its ACE2 receiver and increasing its infection success, resulting in more people infected in a shorter period of time. These mechanisms may also explain why the Spike protein of the Delta variant fused membranes more efficiently at low levels of the cellular receptor ACE2 [22].

There are 5 residues that are highly variable among SARS-CoV-2 VOCs: Y145, K417, T478, E484 and H655 (Figure S3 and Table S1), most of them are exposed in the Spike protein's surface (Figure S4) and are related to evading the immune system. Interestingly, SARS-CoV-2Omicron carries the mutations T478K, E484A, and D614G, all of them important to evade the immune system and for fast spreading of SARS-CoV-2. Moreover, mutations in the RBD of the Omicron variant, such as K417N and N501Y, are predominantly distributed in the interface of its interaction with hACE2 and may have synergistic actions for escaping from neutralizing antibodies [136-138]. In animal model studies, the Omicron variant was shown to be less pathogenic, i.e., to cause milder symptoms, while being 10- 
$20 \%$ more transmissible than the Delta variant. Intriguingly, the Omicron variant also showed to outcompete the Delta variant under immune selection pressure [139].

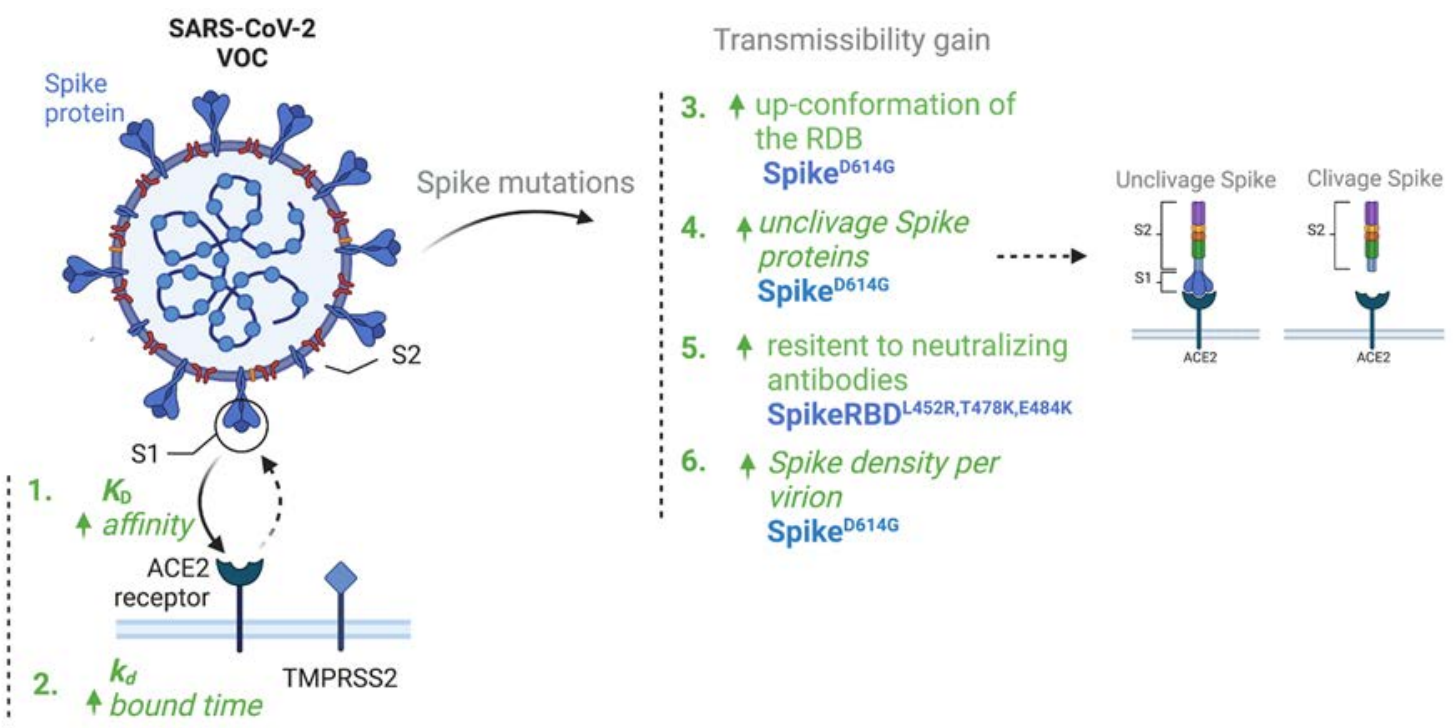

Figure 3. Mutations in the Spike protein of SARS-CoV-2 VOCs result in different mechanisms to evade the immune system, increase the infectiveness, and spread the virus faster in the population. Spike protein of SARS-CoV-2 VOCs increase the hACE2 affinity $\left(K_{D}\right)(1)$; increase the time that the Spike protein is bound to hACE2 $\left(k_{\mathrm{d}}\right)$, favoring the process of membrane fusion (2); increase the up conformation of the RBD in the trimeric state of the Spike protein, a conformation that is able to bind to hACE2 (3); increase the amount of the unclivaged form of the Spike protein in the virion particles (4); different mutations in the RBD improve resistance to neutralizing antibodies (5); and expand the concentration of Spike proteins per viral particles (6). All mechanisms described contribute to Spike's access to hACE2 and to membrane fusion.

\section{Epidemiology of COVID-19}

According to the World Health Organization (WHO), an increase in the number of COVID-19 cases can be observed in the second half of 2021 in countries from the northern hemisphere (Figure 4). Even after the vaccination rates in the United States, United Kingdom, Germany, and Japan surpassed $50 \%$, all these countries had a significant increase in the number of cases and deaths. These data are explained by the emergence of novel variants of SARS-CoV-2 associated with lower efficiency of neutralizing antibodies $[54,140]$. For those countries that surpassed $60 \%$ of the population vaccinated with the first dose, such as Germany and the United Kingdom, the number of deaths was remarkably lower than rates seen during the first wave. Unlike these countries, the United States and Japan had $55.6 \%$ and $37.2 \%$ of the population vaccinated with the first dose, leading the number of deaths to exceed 50\% compared to the first wave of the COVID-19 pandemic. Since Japan has very peculiar characteristics in its historical and behavioral context [141], death and case rates dropped in 11 weeks. However, in the period of the 2021 Olympic Games [142], the country had a significant increase in the number of COVID-19 cases, showing a direct relationship between collective activities, increased circulation and the time of transmission of the Delta variant [143] (Figure 4). It is very evident that the vaccine plays a key role in decreasing death rates from COVID-19. It is estimated that the rate of hospitalization among unvaccinated individuals is 29.2 times higher than those fully vaccinated [144]. Figure 4 shows the prevalence of the Delta and Omicron variants in the United Kingdom, Japan, United States and Germany and the timing of the increase in COVID-19 cases. Delta variant predominance increased from 10 to $90 \%$ in the range of 49 days in the USA, 52 days in Japan, 49 days in the UK and 40 days in Germany (Figure S1). In part, the flexibility of sanitary measures probably contributed to these trajectories, but the emergence of the Omicron variant at the end of 2021 was the main reason for the staggering increase in rates of COVID-19 infection at the beginning of 2022 (Figure 4). The 
UK eased the use of masks on July 19, 2021 [145]. On April 16, 2021, New Hampshire, United States, also relaxed its restrictive measures [146]. Therefore, even with high vaccination rates, the higher numbers of infected people may in part be explained by the relaxation of restrictive measures, which allowed the virus to spread more easily, increasing the likelihood for the emergence of novel variants able to take advantage of any of the several mechanisms, hereby discussed, to evade the immune response, replicate faster or to higher loads and/or to transmit more efficiently (Figure 5).
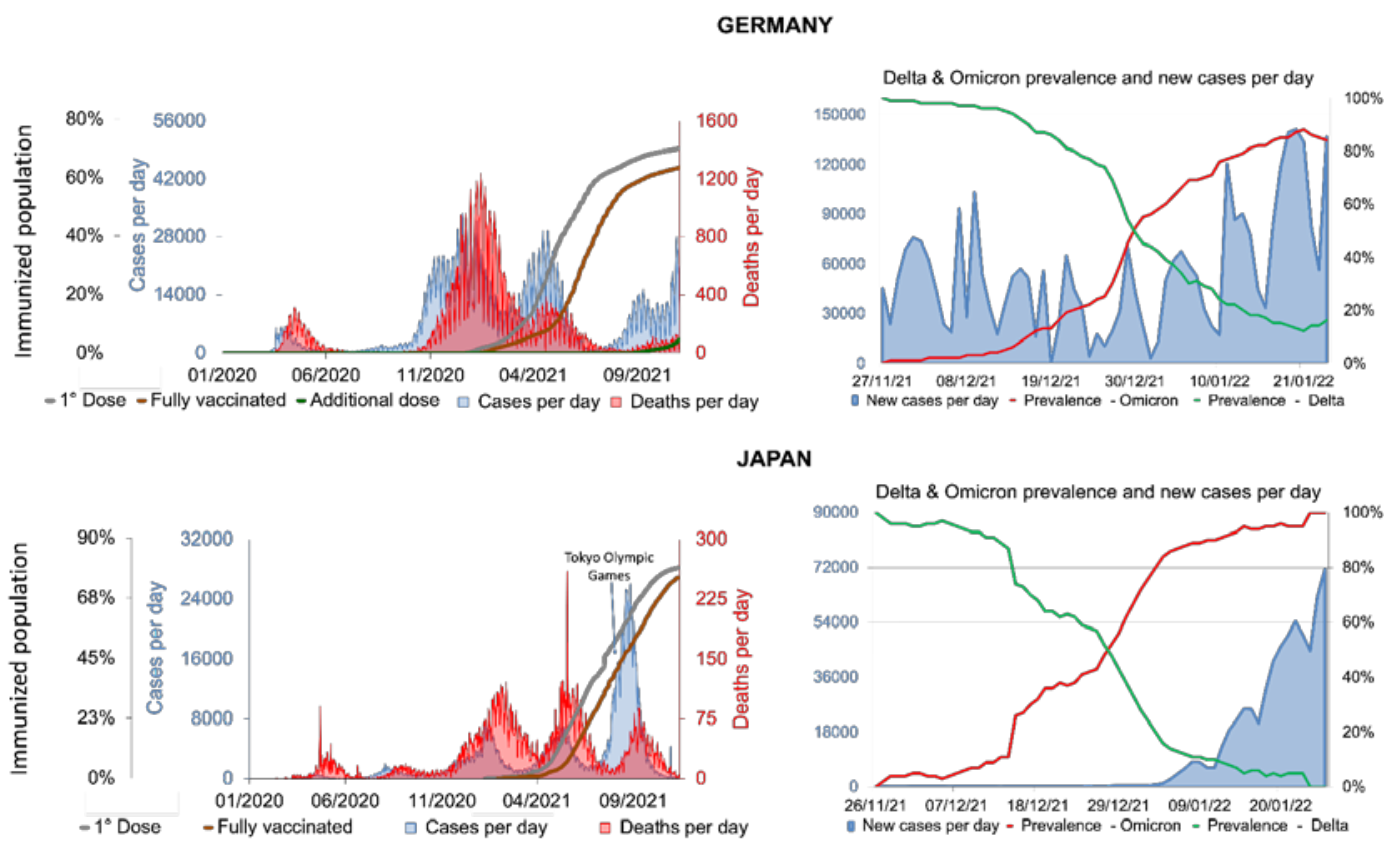

USA
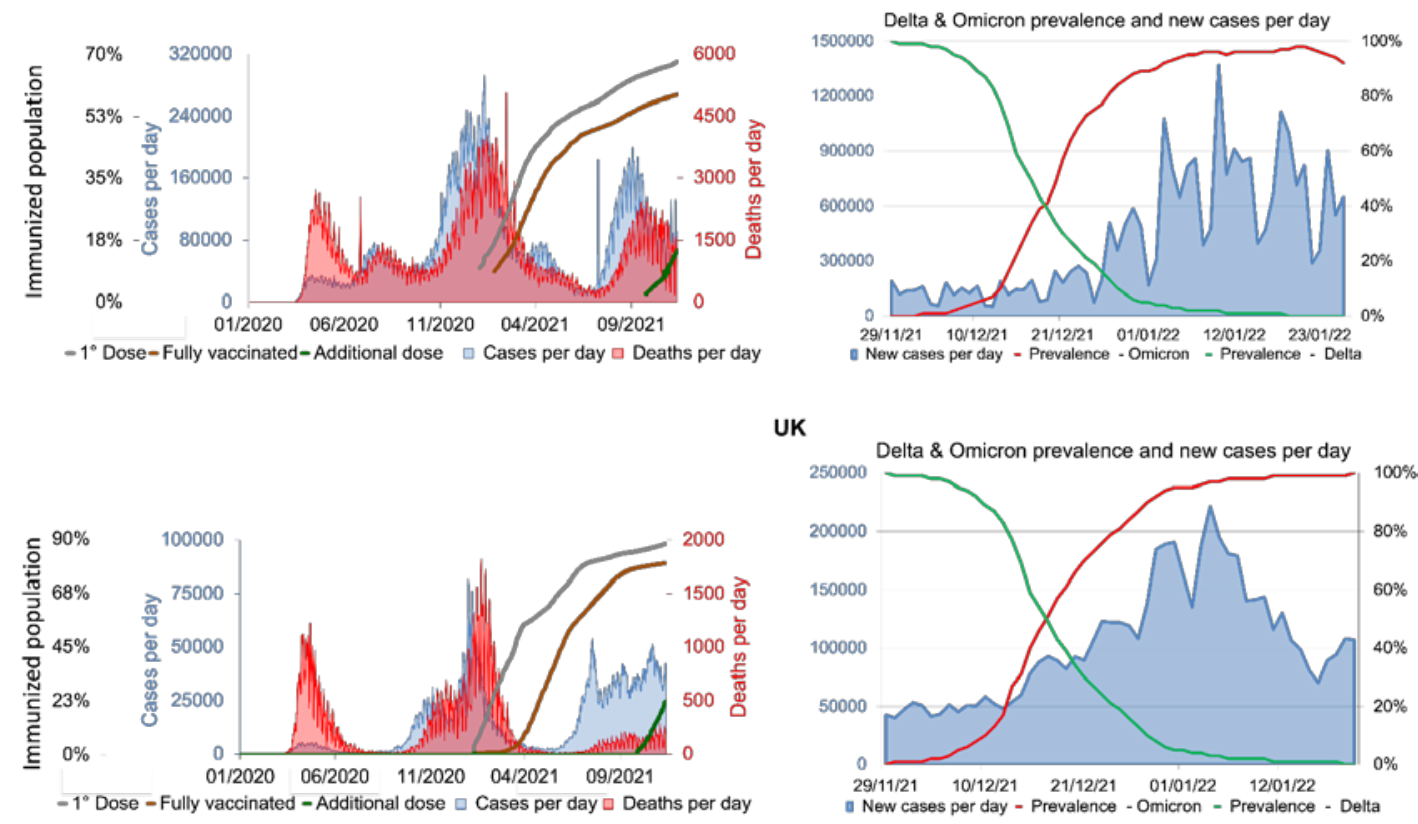

Figure 4. Number of COVID-19 cases and death rates, the effect of vaccination rate, and prevalence of SARS-CoV-2 Delta and Omicron in the UK, Japan, USA, and Germany. On the left side is shown the number of cases (red line), the number of deaths (blue line), the rate of vaccinated individuals with the first dose (gray line), second dose (fully vaccinated, brown line) and additional dose (green line). The right side shows the graph of the number of cases (blue line) and the percentage of the Delta variant (green line) and Omicron variant (red line) as a function of time. All data were obtained from World in Data, WHO, CDC, UK Gov and Outbreak [147-151]. 
COVID-19 Transmission in the Society

(SARS-CoV-2 circulation in the population)

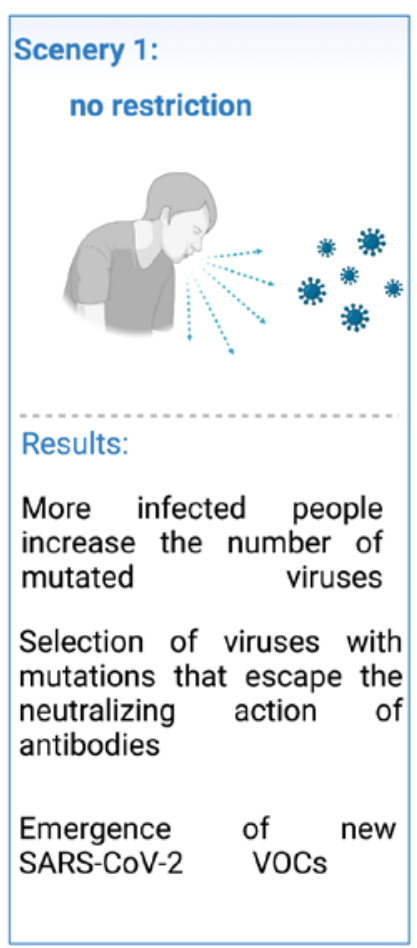

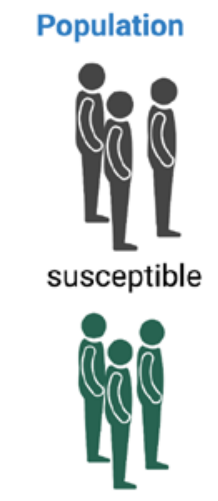

Previoulsly infected (1- 6 months)

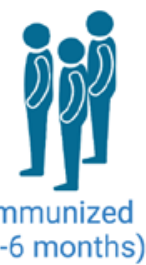

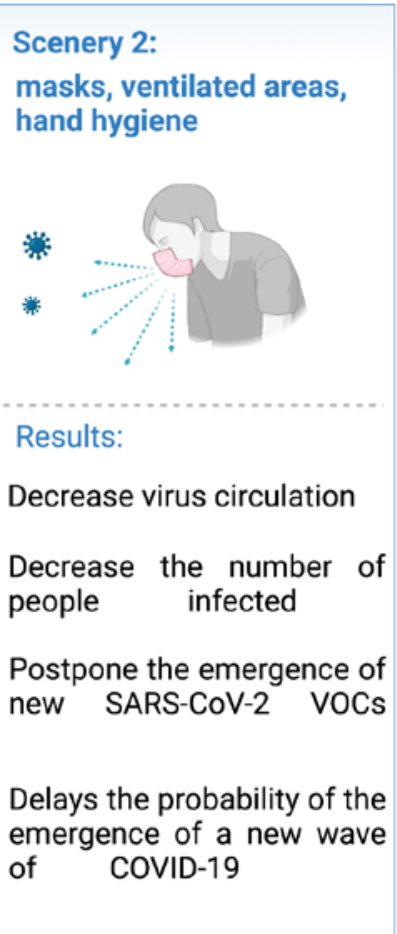

Figure 5. Hypothesis to explain the emergence of novel SARS-CoV-2 variants. Currently, the world population is composed of three groups: those who do not have neutralizing antibodies to Figure 1. in which society does not make any kind of restriction to prevent the spread of the virus, the emergence of VOC should occur faster than in scenario 2, in which society maintains measures to reduce the virus spread. These two scenarios are independent of population immunization, since the virus mutates its genetic information randomly, and selection for variants with more successful infection should prevail in the population. This natural selection seems to be directed towards variants that are able to evade the immune system and spread the virus faster. The SARS-CoV-2 neutralizing antibodies of completely immunized and previously infected individuals kept high until 6 months after immunization or virus infection [152].

\section{CONCLUSION}

In this review, we discussed the SARS-CoV-2 VOC mutations and their impacts on viral infectivity and transmissibility. SARS-CoV-2 has evolved and novel VOCs are still emerging. The route of the actual pandemic is still unknown, but mass worldwide vaccination has been effective to reduce the risk of severe illness, hospitalization, and death from COVID-19, although vaccines were mostly unable to block the spread of the virus. In this regard, restriction measurements to reduce virus spread are also essential to reduce the chances of emergence of new variants capable of evading the immune system, spreading much faster, and with a different tropism than previous strains. All SARS-CoV2 VOCs are of clinical concern, putting at risk the available diagnostic tests and immunization efficiency.

Overall, in the course of viral evolution, mutations occur randomly and those giving some key advantages to the virus are more likely to be selected. In particular, for SARS$\mathrm{CoV}-2$, several mutations fixed in successful variants are located within the Spike protein. Different studies provide evidence that these mutations enable SARS-CoV-2 to more efficiently evade the immune system, even in individuals previously infected or completely immunized. In addition, the VOC's Spike proteins also incorporate changes that increase SARS-CoV-2's infectiveness and transmission efficiency.

The fast spread of many SARS-CoV-2 VOCs is a consequence of many factors, encompassing both host behavior and virus properties. While some Spike mutations lead 
to greater efficacy of infection by increasing the binding affinity to human ACE2 receptors, the same or a few additional mutations may expand the time that Spike remains bound to hACE2, shift the Spike population to the most favorable conformation for receptor binding and increase the number of functional Spike proteins per virion. Most importantly, direct evaluation of the reduced sensitivity of convalescent sera and the observation that vaccinated individuals, while asymptomatic or with mild symptoms, are becoming ever more important for the spread of VOCs, suggests the selection of mutations that allow the virus to evade the immune system is key to explain the success of new variants and is probably going to continue as long as the numbers of novel infections remain high. Taken together these factors play a pivotal role in the emergence of fast spreading SARS-CoV-2 variants of concern, including the Omicron variant.

Acknowledgments: The authors acknowledge the National Council for Scientific and Technological Development (CNPq), the Coordination for the Improvement of Higher Education Personnel (CAPES, grant 88887.374931/2019-00 and 88887.620198/2021-00, Coordenação de Aperfeiçoamento de Pessoal de Nível Superior - Finance Code 01), Rede Virus MCTI (grant FINEP 0459/20). and the São Paulo Research Foundation (FAPESP, grants 2019/00195-2, 2020/04680-0, 2016/09047-8, 2018/07366-4, 2018/15579-8, 2017/19541-2, 2017/18246-7, 2017/17636-6, 2020/14158-9 and 2020/060911), Brazil, for financial support.

Conflicts of Interest: The authors declare no conflict of interest.

\section{References}

1. WHO Coronavirus (COVID-19) Dashboard Available online: https://covid19.who.int/ (accessed on 3 February 2022).

2. Wu, F.; Zhao, S.; Yu, B.; Chen, Y.-M.; Wang, W.; Song, Z.-G.; Hu, Y.; Tao, Z.-W.; Tian, J.-H.; Pei, Y.-Y.; et al. A New Coronavirus Associated with Human Respiratory Disease in China. Nature 2020, 579, 265-269.

3. Harvey, W.T.; Carabelli, A.M.; Jackson, B.; Gupta, R.K.; Thomson, E.C.; Harrison, E.M.; Ludden, C.; Reeve, R.; Rambaut, A.; COVID-19 Genomics UK (COG-UK) Consortium; et al. SARS-CoV-2 Variants, Spike Mutations and Immune Escape. Nat. Rev. Microbiol. 2021, 19, 409-424.

4. Chang, K.W.; Sheng, Y.; Gombold, J.L. Coronavirus-Induced Membrane Fusion Requires the Cysteine-Rich Domain in the Spike Protein. Virology 2000, 269, 212-224.

5. Wrapp, D.; Wang, N.; Corbett, K.S.; Goldsmith, J.A.; Hsieh, C.-L.; Abiona, O.; Graham, B.S.; McLellan, J.S. Cryo-EM Structure of the 2019-nCoV Spike in the Prefusion Conformation. Science 2020, 367, 1260-1263.

6. Walls, A.C.; Park, Y.-J.; Tortorici, M.A.; Wall, A.; McGuire, A.T.; Veesler, D. Structure, Function, and Antigenicity of the SARSCoV-2 Spike Glycoprotein. Cell 2020, 183, 1735.

7. Shulla, A.; Gallagher, T. Role of Spike Protein Endodomains in Regulating Coronavirus Entry. J. Biol. Chem. 2009, 284, 3272532734.

8. Lai, A.L.; Freed, J.H. SARS-CoV-2 Fusion Peptide Has a Greater Membrane Perturbating Effect than SARS-CoV with Highly Specific Dependence on Ca. J. Mol. Biol. 2021, 433, 166946.

9. Xia, S.; Zhu, Y.; Liu, M.; Lan, Q.; Xu, W.; Wu, Y.; Ying, T.; Liu, S.; Shi, Z.; Jiang, S.; et al. Fusion Mechanism of 2019-nCoV and Fusion Inhibitors Targeting HR1 Domain in Spike Protein. Cell. Mol. Immunol. 2020, 17, 765-767.

10. Matsuyama, S.; Nagata, N.; Shirato, K.; Kawase, M.; Takeda, M.; Taguchi, F. Efficient Activation of the Severe Acute Respiratory Syndrome Coronavirus Spike Protein by the Transmembrane Protease TMPRSS2. J. Virol. 2010, 84, 12658-12664.

11. Shulla, A.; Heald-Sargent, T.; Subramanya, G.; Zhao, J.; Perlman, S.; Gallagher, T. A Transmembrane Serine Protease Is Linked to the Severe Acute Respiratory Syndrome Coronavirus Receptor and Activates Virus Entry. J. Virol. 2011, 85, 873-882.

12. Djomkam, A.L.Z.; Olwal, C.O.; Sala, T.B.; Paemka, L. Commentary: SARS-CoV-2 Cell Entry Depends on ACE2 and TMPRSS2 and Is Blocked by a Clinically Proven Protease Inhibitor. Front. Oncol. 2020, 10, 1448.

13. Hoffmann, M.; Kleine-Weber, H.; Schroeder, S.; Krüger, N.; Herrler, T.; Erichsen, S.; Schiergens, T.S.; Herrler, G.; Wu, N.-H.; Nitsche, A.; et al. SARS-CoV-2 Cell Entry Depends on ACE2 and TMPRSS2 and Is Blocked by a Clinically Proven Protease Inhibitor. Cell 2020, 181, 271-280.e8.

14. Madeira, F.; Park, Y.M.; Lee, J.; Buso, N.; Gur, T.; Madhusoodanan, N.; Basutkar, P.; Tivey, A.R.N.; Potter, S.C.; Finn, R.D.; et al. The EMBL-EBI Search and Sequence Analysis Tools APIs in 2019. Nucleic Acids Res. 2019, 47, W636-W641.

15. Landau, M.; Mayrose, I.; Rosenberg, Y.; Glaser, F.; Martz, E.; Pupko, T.; Ben-Tal, N. ConSurf 2005: The Projection of Evolutionary Conservation Scores of Residues on Protein Structures. Nucleic Acids Res. 2005, 33, W299-W302.

16. Glaser, F.; Pupko, T.; Paz, I.; Bell, R.E.; Bechor-Shental, D.; Martz, E.; Ben-Tal, N. ConSurf: Identification of Functional Regions in Proteins by Surface-Mapping of Phylogenetic Information. Bioinformatics 2003, 19, 163-164.

17. Xu, C.; Wang, Y.; Liu, C.; Zhang, C.; Han, W.; Hong, X.; Wang, Y.; Hong, Q.; Wang, S.; Zhao, Q.; et al. Conformational Dynamics of SARS-CoV-2 Trimeric Spike Glycoprotein in Complex with Receptor ACE2 Revealed by Cryo-EM. Sci Adv 2021, 7, doi:10.1126/sciadv.abe5575. 
18. Yang, J.; Petitjean, S.; Derclaye, S.; Koehler, M.; Zhang, Q.; Dumitru, A.C.; Soumillion, P.; Alsteens, D. Molecular Interaction and Inhibition of SARS-CoV-2 Binding to the ACE2 Receptor.

19. Sakkiah, S.; Guo, W.; Pan, B.; Ji, Z.; Yavas, G.; Azevedo, M.; Hawes, J.; Patterson, T.A.; Hong, H. Elucidating Interactions Between SARS-CoV-2 Trimeric Spike Protein and ACE2 Using Homology Modeling and Molecular Dynamics Simulations. Front Chem 2020, 8, 622632.

20. Volz, E.; Hill, V.; McCrone, J.T.; Price, A.; Jorgensen, D.; O’Toole, Á.; Southgate, J.; Johnson, R.; Jackson, B.; Nascimento, F.F.; et al. Evaluating the Effects of SARS-CoV-2 Spike Mutation D614G on Transmissibility and Pathogenicity. Cell 2021, 184, 64-75.e11.

21. Zhou, W.; Wang, W. Fast-Spreading SARS-CoV-2 Variants: Challenges to and New Design Strategies of COVID-19 Vaccines. Signal Transduct Target Ther 2021, 6, 226.

22. Zhang, J.; Xiao, T.; Cai, Y.; Lavine, C.L.; Peng, H.; Zhu, H.; Anand, K.; Tong, P.; Gautam, A.; Mayer, M.L.; et al. Membrane Fusion and Immune Evasion by the Spike Protein of SARS-CoV-2 Delta Variant. Science 2021, 374, 1353-1360.

23. Classification of Omicron (B.1.1.529): SARS-CoV-2 Variant of Concern Available online: https://www.who.int/news/item/26-112021-classification-of-omicron-(b.1.1.529)-sars-cov-2-variant-of-concern (accessed on 17 December 2021).

24. Turkahia, Y.; Thornlow, B.; Hinrichs, A.; McBroome, J.; Ayala, N.; Ye, C.; De Maio, N.; Haussler, D.; Lanfear, R.; Corbett-Detig, R. Pandemic-Scale Phylogenomics Reveals Elevated Recombination Rates in the SARS-CoV-2 Spike Region.

25. Covin, S.; Rutherford, G.W. Coinfection, Severe Acute Respiratory Syndrome Coronavirus 2 (SARS-CoV-2), and Influenza: An Evolving Puzzle. Clin. Infect. Dis. 2021, 72, e993-e994.

26. Cuadrado-Payán, E.; Montagud-Marrahi, E.; Torres-Elorza, M.; Bodro, M.; Blasco, M.; Poch, E.; Soriano, A.; Piñeiro, G.J. SARSCoV-2 and Influenza Virus Co-Infection. The Lancet 2020, 395, e84.

27. Sequence of Mouse Hepatitis Virus A59 mRNA 2: Indications for RNA Recombination between Coronaviruses and Influenza C Virus. Virology 1988, 166, 415-422.

28. Mansbach, R.A.; Chakraborty, S.; Nguyen, K.; Montefiori, D.C.; Korber, B.; Gnanakaran, S. The SARS-CoV-2 Spike Variant D614G Favors an Open Conformational State. Sci Adv 2021, 7, doi:10.1126/sciadv.abf3671.

29. Teruel, N.; Mailhot, O.; Najmanovich, R.J. Modelling Conformational State Dynamics and Its Role on Infection for SARS-CoV2 Spike Protein Variants.

30. Benton, D.J.; Wrobel, A.G.; Roustan, C.; Borg, A.; Xu, P.; Martin, S.R.; Rosenthal, P.B.; Skehel, J.J.; Gamblin, S.J. The Effect of the D614G Substitution on the Structure of the Spike Glycoprotein of SARS-CoV-2. Proc. Natl. Acad. Sci. U. S. A. 2021, 118, doi:10.1073/pnas.2022586118.

31. Benton, D.J.; Wrobel, A.G.; Xu, P.; Roustan, C.; Martin, S.R.; Rosenthal, P.B.; Skehel, J.J.; Gamblin, S.J. Receptor Binding and Priming of the Spike Protein of SARS-CoV-2 for Membrane Fusion. Nature 2020, 588, 327-330.

32. Yurkovetskiy, L.; Wang, X.; Pascal, K.E.; Tomkins-Tinch, C.; Nyalile, T.P.; Wang, Y.; Baum, A.; Diehl, W.E.; Dauphin, A.; Carbone, C.; et al. Structural and Functional Analysis of the D614G SARS-CoV-2 Spike Protein Variant. Cell 2020, 183, 739751.e8.

33. Li, Q.; Wu, J.; Nie, J.; Zhang, L.; Hao, H.; Liu, S.; Zhao, C.; Zhang, Q.; Liu, H.; Nie, L.; et al. The Impact of Mutations in SARSCoV-2 Spike on Viral Infectivity and Antigenicity. Cell 2020, 182, 1284-1294.e9.

34. Banoun, H. Evolution of SARS-CoV-2: Review of Mutations, Role of the Host Immune System. Nephron 2021, 145, $392-403$.

35. Chen, J.; Wang, R.; Wang, M.; Wei, G.-W. Mutations Strengthened SARS-CoV-2 Infectivity. J. Mol. Biol. 2020, 432, 5212-5226.

36. Ku, Z.; Xie, X.; Davidson, E.; Ye, X.; Su, H.; Menachery, V.D.; Li, Y.; Yuan, Z.; Zhang, X.; Muruato, A.E.; et al. Author Correction: Molecular Determinants and Mechanism for Antibody Cocktail Preventing SARS-CoV-2 Escape. Nat. Commun. $2021,12,4177$.

37. Xie, X.; Liu, Y.; Liu, J.; Zhang, X.; Zou, J.; Fontes-Garfias, C.R.; Xia, H.; Swanson, K.A.; Cutler, M.; Cooper, D.; et al. Neutralization of SARS-CoV-2 Spike 69/70 Deletion, E484K and N501Y Variants by BNT162b2 Vaccine-Elicited Sera. Nat. Med. 2021, 27, 620621.

38. Barton, M.I.; MacGowan, S.; Kutuzov, M.; Dushek, O.; Barton, G.J.; van der Merwe, P.A. Effects of Common Mutations in the SARS-CoV-2 Spike RBD Domain and Its Ligand the Human ACE2 Receptor on Binding Affinity and Kinetics.

39. Spratt, A.N.; Kannan, S.R.; Woods, L.T.; Weisman, G.A.; Quinn, T.P.; Lorson, C.L.; Sönnerborg, A.; Byrareddy, S.N.; Singh, K. Factors Associated with Emerging and Re-Emerging of SARS-CoV-2 Variants. bioRxiv 2021, doi:10.1101/2021.03.24.436850.

40. Baum, A.; Fulton, B.O.; Wloga, E.; Copin, R.; Pascal, K.E.; Russo, V.; Giordano, S.; Lanza, K.; Negron, N.; Ni, M.; et al. Antibody Cocktail to SARS-CoV-2 Spike Protein Prevents Rapid Mutational Escape Seen with Individual Antibodies. Science 2020, 369, 1014-1018.

41. Zost, S.J.; Gilchuk, P.; Case, J.B.; Binshtein, E.; Chen, R.E.; Nkolola, J.P.; Schäfer, A.; Reidy, J.X.; Trivette, A.; Nargi, R.S.; et al. Potently Neutralizing and Protective Human Antibodies against SARS-CoV-2. Nature 2020, 584, 443-449.

42. CDC SARS-CoV-2 Variant Classifications and Definitions Available online: https://www.cdc.gov/coronavirus/2019ncov/variants/variant-info.html (accessed on 5 August 2021).

43. Planas, D.; Veyer, D.; Baidaliuk, A.; Staropoli, I.; Guivel-Benhassine, F.; Rajah, M.M.; Planchais, C.; Porrot, F.; Robillard, N.; Puech, J.; et al. Reduced Sensitivity of SARS-CoV-2 Variant Delta to Antibody Neutralization. Nature 2021, doi:10.1038/s41586021-03777-9.

44. Padilla-Sanchez, V. Molecular Dynamics of SARS-CoV-2 Delta Variant Receptor Binding Domain in Complex with ACE2 Receptor.

45. Kim, S.; Liu, Y.; Lei, Z.; Dicker, J.; Cao, Y.; Frank Zhang, X.; Im, W. Differential Interactions Between Human ACE2 and Spike RBD of SARS-CoV-2 Variants of Concern. 
46. Bergman, N.K.; Fishman, R. Mobility Reduction and Covid-19 Transmission Rates.

47. National Center for Immunization and Respiratory Diseases (NCIRD), Division of Viral Diseases Science Brief: COVID-19 Vaccines and Vaccination. In CDC COVID-19 Science Briefs; Centers for Disease Control and Prevention (US): Atlanta (GA), 2021.

48. Mannar, D.; Saville, J.W.; Zhu, X.; Srivastava, S.S.; Berezuk, A.M.; Tuttle, K.S.; Marquez, A.C.; Sekirov, I.; Subramaniam, S. SARS-CoV-2 Omicron Variant: Antibody Evasion and Cryo-EM Structure of Spike Protein-ACE2 Complex. Science 2022, eabn7760.

49. Zhang, J.; Cai, Y.; Xiao, T.; Lu, J.; Peng, H.; Sterling, S.M.; Walsh, R.M., Jr; Rits-Volloch, S.; Zhu, H.; Woosley, A.N.; et al. Structural Impact on SARS-CoV-2 Spike Protein by D614G Substitution. Science 2021, 372, 525-530.

50. Zhang, L.; Jackson, C.B.; Mou, H.; Ojha, A.; Peng, H.; Quinlan, B.D.; Rangarajan, E.S.; Pan, A.; Vanderheiden, A.; Suthar, M.S.; et al. SARS-CoV-2 Spike-Protein D614G Mutation Increases Virion Spike Density and Infectivity. Nat. Commun. 2020, 11, 1-9.

51. Wu, K.; Chen, L.; Peng, G.; Zhou, W.; Pennell, C.A.; Mansky, L.M.; Geraghty, R.J.; Li, F. A Virus-Binding Hot Spot on Human Angiotensin-Converting Enzyme 2 Is Critical for Binding of Two Different Coronaviruses. J. Virol. 2011, 85, $5331-5337$.

52. Yi, C.; Sun, X.; Ye, J.; Ding, L.; Liu, M.; Yang, Z.; Lu, X.; Zhang, Y.; Ma, L.; Gu, W.; et al. Key Residues of the Receptor Binding Motif in the Spike Protein of SARS-CoV-2 That Interact with ACE2 and Neutralizing Antibodies. Cell. Mol. Immunol. 2020, 17, 621-630.

53. Shang, J.; Ye, G.; Shi, K.; Wan, Y.; Luo, C.; Aihara, H.; Geng, Q.; Auerbach, A.; Li, F. Structural Basis of Receptor Recognition by SARS-CoV-2. Nature 2020, 581, 221-224.

54. de Souza, A.S.; de Freitas Amorim, V.M.; Guardia, G.D.A.; dos Santos, F.R.C.; dos Santos, F.F.; de Souza, R.F.; de Araujo Juvenal, G.; Huang, Y.; Ge, P.; Jiang, Y.; et al. Molecular Dynamics Analysis of Fast-Spreading Severe Acute Respiratory Syndrome Coronavirus 2 Variants and Their Effects in the Interaction with Human Angiotensin-Converting Enzyme 2. bioRxiv 2021, 2021.06.14.448436.

55. Silva de Souza, A.; Rivera, J.D.; Almeida, V.M.; Ge, P.; de Souza, R.F.; Farah, C.S.; Ulrich, H.; Marana, S.R.; Salinas, R.K.; Guzzo, C.R. Molecular Dynamics Reveals Complex Compensatory Effects of Ionic Strength on the Severe Acute Respiratory Syndrome Coronavirus 2 Spike/Human Angiotensin-Converting Enzyme 2 Interaction. J. Phys. Chem. Lett. 2020, 11, 10446-10453.

56. Ramanathan, M.; Ferguson, I.D.; Miao, W.; Khavari, P.A. SARS-CoV-2 B.1.1.7 and B.1.351 Spike Variants Bind Human ACE2 with Increased Affinity.

57. Tian, F.; Tong, B.; Sun, L.; Shi, S.; Zheng, B.; Wang, Z.; Dong, X.; Zheng, P. Mutation N501Y in RBD of Spike Protein Strengthens the Interaction between COVID-19 and Its Receptor ACE2.

58. Laffeber, C.; de Koning, K.; Kanaar, R.; Lebbink, J.H.G. Experimental Evidence for Enhanced Receptor Binding by Rapidly Spreading SARS-CoV-2 Variants.

59. Vogel, M.; Augusto, G.S.; Chang, X.; Liu, X.; Speiser, D.; Mohsen, M.O.; Bachmann, M.F. Molecular Definition of SARS-CoV-2 RBD Mutations: Receptor Affinity versus Neutralization of Receptor Interaction. Allergy 2021, doi:10.1111/all.15002.

60. Ozono, S.; Zhang, Y.; Ode, H.; Sano, K.; Tan, T.S.; Imai, K.; Miyoshi, K.; Kishigami, S.; Ueno, T.; Iwatani, Y.; et al. SARS-CoV-2 D614G Spike Mutation Increases Entry Efficiency with Enhanced ACE2-Binding Affinity. Nat. Commun. 2021, $12,848$.

61. Cai, Y.; Zhang, J.; Xiao, T.; Lavine, C.L.; Rawson, S.; Peng, H.; Zhu, H.; Anand, K.; Tong, P.; Gautam, A.; et al. Structural Basis for Enhanced Infectivity and Immune Evasion of SARS-CoV-2 Variants. Science 2021, doi:10.1126/science.abi9745.

62. Ren, W.; Ju, X.; Gong, M.; Lan, J.; Yu, Y.; Long, Q.; Zhang, Y.; Zhong, J.; Zhong, G.; Wang, X.; et al. Characterization of SARSCoV-2 Variants B.1.617.1 (Kappa), B.1.617.2 (Delta) and B.1.618 on Cell Entry, Host Range, and Sensitivity to Convalescent Plasma and ACE2 Decoy Receptor.

63. GISAID - hCov19 Variants Available online: https://www.gisaid.org/hcov19-variants/ (accessed on 3 February 2022).

64. Wang, P.; Casner, R.G.; Nair, M.S.; Wang, M.; Yu, J.; Cerutti, G.; Liu, L.; Kwong, P.D.; Huang, Y.; Shapiro, L.; et al. Increased Resistance of SARS-CoV-2 Variant P.1 to Antibody Neutralization. Cell Host Microbe 2021, 29, 747-751.e4.

65. Farinholt, T.; Doddapaneni, H.; Qin, X.; Menon, V.; Meng, Q.; Metcalf, G.; Chao, H.; Gingras, M.-C.; Farinholt, P.; Agrawal, C.; et al. Transmission Event of SARS-CoV-2 Delta Variant Reveals Multiple Vaccine Breakthrough Infections. medRxiv 2021, 2021.06.28.21258780.

66. Cameroni, E.; Saliba, C.; Bowen, J.E.; Rosen, L.E.; Culap, K.; Pinto, D.; VanBlargan, L.A.; De Marco, A.; Zepeda, S.K.; Iulio, J. di; et al. Broadly Neutralizing Antibodies Overcome SARS-CoV-2 Omicron Antigenic Shift. bioRxiv 2021, doi:10.1101/2021.12.12.472269.

67. Lamers, M.M.; Mykytyn, A.Z.; Breugem, T.I.; Groen, N.; Knoops, K.; Schipper, D.; van Acker, R.; van den Doel, P.B.; Bestebroer, T.; Koopman, C.D.; et al. SARS-CoV-2 Omicron Efficiently Infects Human Airway, but Not Alveolar Epithelium. bioRxiv 2022.

68. Ong, S.W.X.; Chiew, C.J.; Ang, L.W.; Mak, T.-M.; Cui, L.; Toh, M.P.H.S.; Lim, Y.D.; Lee, P.H.; Lee, T.H.; Chia, P.Y.; et al. Clinical and Virological Features of SARS-CoV-2 Variants of Concern: A Retrospective Cohort Study Comparing B.1.1.7 (Alpha), B.1.315 (Beta), and B.1.617.2 (Delta). Clin. Infect. Dis. 2021, doi:10.1093/cid/ciab721.

69. Charmet, T.; Schaeffer, L.; Grant, R.; Galmiche, S.; Chény, O.; Von Platen, C.; Maurizot, A.; Rogoff, A.; Omar, F.; David, C.; et al. Impact of Original, B.1.1.7, and B.1.351/P.1 SARS-CoV-2 Lineages on Vaccine Effectiveness of Two Doses of COVID-19 mRNA Vaccines: Results from a Nationwide Case-Control Study in France. The Lancet Regional Health - Europe 2021, 8, 100171.

70. Campbell, F.; Archer, B.; Laurenson-Schafer, H.; Jinnai, Y.; Konings, F.; Batra, N.; Pavlin, B.; Vandemaele, K.; Van Kerkhove, M.D.; Jombart, T.; et al. Increased Transmissibility and Global Spread of SARS-CoV-2 Variants of Concern as at June 2021. Eurosurveillance 2021, 26. 
71. Wölfel, R.; Corman, V.M.; Guggemos, W.; Seilmaier, M.; Zange, S.; Müller, M.A.; Niemeyer, D.; Jones, T.C.; Vollmar, P.; Rothe, C.; et al. Virological Assessment of Hospitalized Patients with COVID-2019. Nature 2020, 581, 465-469.

72. He, X.; Lau, E.H.Y.; Wu, P.; Deng, X.; Wang, J.; Hao, X.; Lau, Y.C.; Wong, J.Y.; Guan, Y.; Tan, X.; et al. Temporal Dynamics in Viral Shedding and Transmissibility of COVID-19. Nat. Med. 2020, 26, 672-675.

73. Silva, M.V.R.; de Castro, M.V.; Passos-Bueno, M.R.; Otto, P.A.; Naslavsky, M.S.; Zatz, M. Men Are the Main COVID-19 Transmitters: Lessons from Couples. bioRxiv 2021.

74. Breban, R.; Riou, J.; Fontanet, A. Interhuman Transmissibility of Middle East Respiratory Syndrome Coronavirus: Estimation of Pandemic Risk. Lancet 2013, 382, 694-699.

75. D'Arienzo, M.; Coniglio, A. Assessment of the SARS-CoV-2 Basic Reproduction Number, R0, Based on the Early Phase of COVID-19 Outbreak in Italy. Biosafety and Health 2020, 2, 57-59.

76. Leung, K.; Pei, Y.; Leung, G.M.; Lam, T.T.Y.; Wu, J.T. Empirical Transmission Advantage of the D614G Mutant Strain of SARSCoV-2. medRxiv 2020, 2020.09.22.20199810.

77. Plante, J.A.; Liu, Y.; Liu, J.; Xia, H.; Johnson, B.A.; Lokugamage, K.G.; Zhang, X.; Muruato, A.E.; Zou, J.; Fontes-Garfias, C.R.; et al. Spike Mutation D614G Alters SARS-CoV-2 Fitness. Nature 2021, 592, 116-121.

78. Davies, N.G.; Abbott, S.; Barnard, R.C.; Jarvis, C.I.; Kucharski, A.J.; Munday, J.D.; Pearson, C.A.B.; Russell, T.W.; Tully, D.C.; Washburne, A.D.; et al. Estimated Transmissibility and Impact of SARS-CoV-2 Lineage B.1.1.7 in England. Science 2021, 372, doi:10.1126/science.abg3055.

79. CDC SARS-CoV-2 Variant Classifications and Definitions Available online: https://www.cdc.gov/coronavirus/2019ncov/variants/variant-info.html (accessed on 9 July 2021).

80. Lippi, G.; Henry, B.M. How Will Emerging SARS-CoV-2 Variants Impact Herd Immunity? Ann Transl Med $2021,9,585$.

81. Coutinho, R.M.; Marquitti, F.M.D.; Ferreira, L.S.; Borges, M.E.; da Silva, R.L.P.; Canton, O.; Portella, T.P.; Poloni, S.; Franco, C.; Plucinski, M.M.; et al. Model-Based Estimation of Transmissibility and Reinfection of SARS-CoV-2 P.1 Variant. medRxiv 2021, 2021.03.03.21252706.

82. Website Available online: https://doi.org/10.1016/S2213-2600(21)00559-2.

83. JingLu Viral Infection and Transmission in a Large Well-Traced Outbreak Caused by the Delta SARS-CoV-2 Variant Available online: https://virological.org/t/viral-infection-and-transmission-in-a-large-well-traced-outbreak-caused-by-the-delta-sars-cov2-variant/724 (accessed on 3 February 2022).

84. Kidd, M.; Richter, A.; Best, A.; Cumley, N.; Mirza, J.; Percival, B.; Mayhew, M.; Megram, O.; Ashford, F.; White, T.; et al. SVariant SARS-CoV-2 Lineage B1.1.7 Is Associated With Significantly Higher Viral Load in Samples Tested by TaqPath Polymerase Chain Reaction. J. Infect. Dis. 2021, 223, 1666-1670.

85. Singanayagam, A.; Hakki, S.; Dunning, J.; Madon, K.J.; Crone, M.A.; Koycheva, A.; Derqui-Fernandez, N.; Barnett, J.L.; Whitfield, M.G.; Varro, R.; et al. Community Transmission and Viral Load Kinetics of the SARS-CoV-2 Delta (B.1.617.2) Variant in Vaccinated and Unvaccinated Individuals in the UK: A Prospective, Longitudinal, Cohort Study. The Lancet Infectious Diseases 2021.

86. Mallapaty, S. Delta's Rise Is Fuelled by Rampant Spread from People Who Feel Fine. Nature 2021.

87. Homma, Y.; Katsuta, T.; Oka, H.; Inoue, K.; Toyoshima, C.; Iwaki, H.; Yamashita, Y.; Shinomiya, H. The Incubation Period of the SARS-CoV-2 B1.1.7 Variant Is Shorter than that of Other Strains. J. Infect. 2021, 83, e15-e17.

88. Wiersinga, W.J.; Rhodes, A.; Cheng, A.C.; Peacock, S.J.; Prescott, H.C. Pathophysiology, Transmission, Diagnosis, and Treatment of Coronavirus Disease 2019 (COVID-19): A Review. JAMA 2020, 324, 782-793.

89. Li W.Y.; Du Z.C.; Wang Y.; Lin X.; Lu L.; Fang Q.; Zhang W.F.; Cai M.W.; Xu L.; Hao Y.T. [Epidemiological characteristics of local outbreak of COVID-19 caused by SARS-CoV-2 Delta variant in Liwan district, Guangzhou]. Zhonghua Liu Xing Bing Xue Za Zhi 2021, 42, 1763-1768.

90. Lu, J.; Li, B.; Deng, A.; Li, K.; Hu, Y.; Li, Z.; Xiong, Q.; Liu, Z.; Guo, Q.; Zou, L.; et al. Viral Infection and Transmission in a Large, Well-Traced Outbreak Caused by the SARS-CoV-2 Delta Variant.

91. Beniac, D.R.; Andonov, A.; Grudeski, E.; Booth, T.F. Architecture of the SARS Coronavirus Prefusion Spike. Nat. Struct. Mol. Biol. 2006, 13, 751-752.

92. Chu, V.C.; McElroy, L.J.; Chu, V.; Bauman, B.E.; Whittaker, G.R. The Avian Coronavirus Infectious Bronchitis Virus Undergoes Direct Low-pH-Dependent Fusion Activation during Entry into Host Cells. J. Virol. 2006, 80, 3180-3188.

93. Keyaerts, E.; Vijgen, L.; Maes, P.; Duson, G.; Neyts, J.; Van Ranst, M. Viral Load Quantitation of SARS-Coronavirus RNA Using a One-Step Real-Time RT-PCR. Int. J. Infect. Dis. 2006, 10, 32-37.

94. Yao, H.; Song, Y.; Chen, Y.; Wu, N.; Xu, J.; Sun, C.; Zhang, J.; Weng, T.; Zhang, Z.; Wu, Z.; et al. Molecular Architecture of the SARS-CoV-2 Virus. Cell 2020, 183, 730-738.

95. Wang, Q.; Nair, M.S.; Anang, S.; Zhang, S.; Nguyen, H.T.; Huang, Y.; Liu, L.; Ho, D.D.; Sodroski, J. Functional Differences Among the Spike Glycoproteins of Emerging Sars-Cov-2 Variants B.1.1.7, B.1.351, P.1 and B.1.1.248. SSRN Electronic Journal.

96. Korber, B.; Fischer, W.M.; Gnanakaran, S.; Yoon, H.; Theiler, J.; Abfalterer, W.; Hengartner, N.; Giorgi, E.E.; Bhattacharya, T.; Foley, B.; et al. Tracking Changes in SARS-CoV-2 Spike: Evidence That D614G Increases Infectivity of the COVID-19 Virus. Cell 2020, 182, 812-827.e19.

97. Daniloski, Z.; Jordan, T.X.; Ilmain, J.K.; Guo, X.; Bhabha, G.; tenOever, B.R.; Sanjana, N.E. The Spike D614G Mutation Increases SARS-CoV-2 Infection of Multiple Human Cell Types. Elife 2021, 10, doi:10.7554/eLife.65365. 
98. Calistri, P.; Amato, L.; Puglia, I.; Cito, F.; Di Giuseppe, A.; Danzetta, M.L.; Morelli, D.; Di Domenico, M.; Caporale, M.; Scialabba, S.; et al. Infection Sustained by Lineage B.1.1.7 of SARS-CoV-2 Is Characterised by Longer Persistence and Higher Viral RNA Loads in Nasopharyngeal Swabs. International Journal of Infectious Diseases 2021, 105, 753-755.

99. De Smet, D.; Vanhee, M.; Maes, B.; Swaerts, K.; De Jaeger, P.; Van Hoecke, F.; Maelegheer, K.; Martens, G.A. Cycle Threshold Probability Score for Immediate and Sensitive Detection of B.1.351 SARS-CoV-2 Lineage. 2021, doi:10.21203/rs.3.rs-558631/v1.

100. Naveca, F.; Nascimento, V.; Souza, V.; Corado, A.; Nascimento, F.; Silva, G.; Costa, Á.; Duarte, D.; Pessoa, K.; Mejía, M.; et al. COVID-19 Epidemic in the Brazilian State of Amazonas Was Driven by Long-Term Persistence of Endemic SARS-CoV-2 Lineages and the Recent Emergence of the New Variant of Concern P.1. 2021, doi:10.21203/rs.3.rs-275494/v1.

101. Williams, T.C.; Burgers, W.A. SARS-CoV-2 Evolution and Vaccines: Cause for Concern? Lancet Respir. Med. $2021,9,333-335$.

102. Gao, Q.; Bao, L.; Mao, H.; Wang, L.; Xu, K.; Yang, M.; Li, Y.; Zhu, L.; Wang, N.; Lv, Z.; et al. Development of an Inactivated Vaccine Candidate for SARS-CoV-2. Science 2020, 369, 77-81.

103. The Sinovac COVID-19 Vaccine: What You Need to Know Available online: https://www.who.int/news-room/featurestories/detail/the-sinovac-covid-19-vaccine-what-you-need-to-know (accessed on 9 July 2021).

104. Ramasamy, M.N.; Jessop, L.J. CoronaVac: More Data for Regulators and Policy Makers. Lancet 2021, doi:10.1016/s01406736(21)01543-9.

105. Han, B.; Song, Y.; Li, C.; Yang, W.; Ma, Q.; Jiang, Z.; Li, M.; Lian, X.; Jiao, W.; Wang, L.; et al. Safety, Tolerability, and Immunogenicity of an Inactivated SARS-CoV-2 Vaccine (CoronaVac) in Healthy Children and Adolescents: A Double-Blind, Randomised, Controlled, Phase 1/2 Clinical Trial. Lancet Infect. Dis. 2021, doi:10.1016/S1473-3099(21)00319-4.

106. Zhang, Y.; Zeng, G.; Pan, H.; Li, C.; Kan, B.; Hu, Y.; Mao, H.; Xin, Q.; Chu, K.; Han, W.; et al. Immunogenicity and Safety of a SARS-CoV-2 Inactivated Vaccine in Healthy Adults Aged 18-59 Years: Report of the Randomized, Double-Blind, and PlaceboControlled Phase 2 Clinical Trial. bioRxiv 2020.

107. Ella, R.; Reddy, S.; Blackwelder, W.; Potdar, V.; Yadav, P.; Sarangi, V.; Aileni, V.K.; Kanungo, S.; Rai, S.; Reddy, P.; et al. Efficacy, Safety, and Lot to Lot Immunogenicity of an Inactivated SARS-CoV-2 Vaccine (BBV152): A, Double-Blind, Randomised, Controlled Phase 3 Trial. medRxiv 2021, 2021.06.30.21259439.

108. Sapkal, G.N.; Yadav, P.D.; Ella, R.; Deshpande, G.R.; Sahay, R.R.; Gupta, N.; Vadrevu, K.M.; Abraham, P.; Panda, S.; Bhargava, B. Inactivated COVID-19 Vaccine BBV152/COVAXIN Effectively Neutralizes Recently Emerged B.1.1.7 Variant of SARS-CoV2. J. Travel Med. 2021, 28, doi:10.1093/jtm/taab051.

109. Yadav, P.D.; Sapkal, G.N.; Ella, R.; Sahay, R.R.; Nyayanit, D.A.; Patil, D.Y.; Deshpande, G.; Shete, A.M.; Gupta, N.; Mohan, V.K.; et al. Neutralization against B.1.351 and B.1.617.2 with Sera of COVID-19 Recovered Cases and Vaccinees of BBV152. bioRxiv 2021.

110. Heath, P.T.; Galiza, E.P.; Baxter, D.N.; Boffito, M.; Browne, D.; Burns, F.; Chadwick, D.R.; Clark, R.; Cosgrove, C.; Galloway, J.; et al. Safety and Efficacy of NVX-CoV2373 Covid-19 Vaccine. N. Engl. J. Med. 2021, doi:10.1056/NEJMoa2107659.

111. Jones, I.; Roy, P. Sputnik V COVID-19 Vaccine Candidate Appears Safe and Effective. Lancet 2021, 397, $642-643$.

112. Knoll, M.D.; Wonodi, C. Oxford-AstraZeneca COVID-19 Vaccine Efficacy. Lancet 2021, 397, 72-74.

113. CDC Johnson \& Johnson's Janssen COVID-19 Vaccine Overview and Safety Available online: https://www.cdc.gov/coronavirus/2019-ncov/vaccines/different-vaccines/janssen.html (accessed on 11 July 2021).

114. CDC Moderna COVID-19 Vaccine Overview and Safety Available online: https://www.cdc.gov/coronavirus/2019ncov/vaccines/different-vaccines/Moderna.html (accessed on 11 July 2021).

115. Chemaitelly, H.; Yassine, H.M.; Benslimane, F.M.; Al Khatib, H.A.; Tang, P.; Hasan, M.R.; Malek, J.A.; Coyle, P.; Ayoub, H.H.; Al Kanaani, Z.; et al. mRNA-1273 COVID-19 Vaccine Effectiveness against the B.1.1.7 and B.1.351 Variants and Severe COVID19 Disease in Qatar. Nature Medicine 2021.

116. CDC Pfizer-BioNTech COVID-19 Vaccine Overview and Safety Available online: https://www.cdc.gov/coronavirus/2019ncov/vaccines/different-vaccines/Pfizer-BioNTech.html (accessed on 11 July 2021).

117. CDC COVID-19 Vaccines for Children and Teens Available online: https://www.cdc.gov/coronavirus/2019ncov/vaccines/recommendations/children-teens.html (accessed on 2 February 2022).

118. Bernal, J.L.; Andrews, N.; Gower, C.; Gallagher, E.; Simmons, R.; Thelwall, S.; Stowe, J.; Tessier, E.; Groves, N.; Dabrera, G.; et al. Effectiveness of COVID-19 Vaccines against the B.1.617.2 Variant. bioRxiv 2021.

119. Casadevall, A.; Henderson, J.P.; Joyner, M.J.; Pirofski, L.-A. SARS-CoV-2 Variants and Convalescent Plasma: Reality, Fallacies, and Opportunities. J. Clin. Invest. 2021, 131, doi:10.1172/JCI148832.

120. Andreano, E.; Piccini, G.; Licastro, D.; Casalino, L.; Johnson, N.V.; Paciello, I.; Monego, S.D.; Pantano, E.; Manganaro, N.; Manenti, A.; et al. SARS-CoV-2 Escape from a Highly Neutralizing COVID-19 Convalescent Plasma. bioRxiv 2020, doi:10.1101/2020.12.28.424451.

121. Robbiani, D.F.; Gaebler, C.; Muecksch, F.; Lorenzi, J.C.C.; Wang, Z.; Cho, A.; Agudelo, M.; Barnes, C.O.; Gazumyan, A.; Finkin, S.; et al. Convergent Antibody Responses to SARS-CoV-2 in Convalescent Individuals. Nature 2020, 584, 437-442.

122. Liu, L.; Fang, Q.; Deng, F.; Wang, H.; Yi, C.E.; Ba, L.; Yu, W.; Lin, R.D.; Li, T.; Hu, Z.; et al. Natural Mutations in the Receptor Binding Domain of Spike Glycoprotein Determine the Reactivity of Cross-Neutralization between Palm Civet Coronavirus and Severe Acute Respiratory Syndrome Coronavirus. J. Virol. 2007, 81, 4694-4700.

123. Liu, C.; Ginn, H.M.; Dejnirattisai, W.; Supasa, P.; Wang, B.; Tuekprakhon, A.; Nutalai, R.; Zhou, D.; Mentzer, A.J.; Zhao, Y.; et al. Reduced Neutralization of SARS-CoV-2 B.1.617 by Vaccine and Convalescent Serum. Cell 2021, doi:10.1016/j.cell.2021.06.020. 
124. Tada, T.; Zhou, H.; Samanovic, M.I.; Dcosta, B.M.; Cornelius, A.; Mulligan, M.J.; Landau, N.R. Comparison of Neutralizing Antibody Titers Elicited by mRNA and Adenoviral Vector Vaccine against SARS-CoV-2 Variants.

125. Vacharathit, V.; Aiewsakun, P.; Manopwisedjaroen, S.; Srisaowakarn, C.; Laopanupong, T.; Ludowyke, N.; Phuphuakrat, A.; Setthaudom, C.; Ekronarongchai, S.; Srichatrapimuk, S.; et al. SARS-CoV-2 Variants of Concern Exhibit Reduced Sensitivity to Live-Virus Neutralization in Sera from CoronaVac Vaccinees and Naturally Infected COVID-19 Patients.

126. Ikegame, S.; Siddiquey, M.; Hung, C.-T.; Haas, G.; Brambilla, L.; Oguntuyo, K.; Kowdle, S.; Vilardo, A.; Edelstein, A.; Perandones, C.; et al. Neutralizing Activity of Sputnik V Vaccine Sera against SARS-CoV-2 Variants. Res Sq 2021, doi:10.21203/rs.3.rs-400230/v1.

127. Jongeneelen, M.; Kaszas, K.; Veldman, D.; Huizingh, J.; van der Vlugt, R.; Schouten, T.; Zuijdgeest, D.; Uil, T.; van Roey, G.; Guimera, N.; et al. Ad26.COV2.S Elicited Neutralizing Activity against Delta and Other SARS-CoV-2 Variants of Concern.

128. Yadav, P.D.; Sapkal, G.N.; Ella, R.; Sahay, R.R.; Nyayanit, D.A.; Patil, D.Y.; Deshpande, G.; Shete, A.M.; Gupta, N.; Krishna Mohan, V.; et al. Neutralization of Beta and Delta Variant with Sera of COVID-19 Recovered Cases and Vaccinees of Inactivated COVID-19 Vaccine BBV152/Covaxin. Journal of Travel Medicine 2021.

129. Lee, W.S.; Wheatley, A.K.; Kent, S.J.; DeKosky, B.J. Antibody-Dependent Enhancement and SARS-CoV-2 Vaccines and Therapies. Nat Microbiol 2020, 5, 1185-1191.

130. Arvin, A.M.; Fink, K.; Schmid, M.A.; Cathcart, A.; Spreafico, R.; Havenar-Daughton, C.; Lanzavecchia, A.; Corti, D.; Virgin, H.W. A Perspective on Potential Antibody-Dependent Enhancement of SARS-CoV-2. Nature 2020, 584, $353-363$.

131. Bournazos, S.; Gupta, A.; Ravetch, J.V. The Role of IgG Fc Receptors in Antibody-Dependent Enhancement. Nat. Rev. Immunol. 2020, 20, 633-643.

132. Cloutier, M.; Nandi, M.; Ihsan, A.U.; Chamard, H.A.; Ilangumaran, S.; Ramanathan, S. ADE and Hyperinflammation in SARSCoV2 Infection- Comparison with Dengue Hemorrhagic Fever and Feline Infectious Peritonitis. Cytokine 2020, 136, 155256.

133. Maemura, T.; Kuroda, M.; Armbrust, T.; Yamayoshi, S.; Halfmann, P.J.; Kawaoka, Y. Antibody-Dependent Enhancement of SARS-CoV-2 Infection Is Mediated by the IgG Receptors Fc $\gamma$ RIIA and Fc $\gamma$ RIIIA but Does Not Contribute to Aberrant Cytokine Production by Macrophages. MBio 2021, 12, e0198721.

134. Zheng, J.; Wang, Y.; Li, K.; Meyerholz, D.K.; Allamargot, C.; Perlman, S. Severe Acute Respiratory Syndrome Coronavirus 2Induced Immune Activation and Death of Monocyte-Derived Human Macrophages and Dendritic Cells. J. Infect. Dis. 2021, 223, 785-795.

135. Hui, K.P.Y.; Cheung, M.-C.; Perera, R.A.P.M.; Ng, K.-C.; Bui, C.H.T.; Ho, J.C.W.; Ng, M.M.T.; Kuok, D.I.T.; Shih, K.C.; Tsao, S.W.; et al. Tropism, Replication Competence, and Innate Immune Responses of the Coronavirus SARS-CoV-2 in Human Respiratory Tract and Conjunctiva: An Analysis in Ex-Vivo and in-Vitro Cultures. Lancet Respir Med 2020, 8, $687-695$.

136. Hastie, K.M.; Li, H.; Bedinger, D.; Schendel, S.L.; Dennison, S.M.; Li, K.; Rayaprolu, V.; Yu, X.; Mann, C.; Zandonatti, M.; et al. Defining Variant-Resistant Epitopes Targeted by SARS-CoV-2 Antibodies: A Global Consortium Study. Science 2021, 374, 472478.

137. Alenquer, M.; Ferreira, F.; Lousa, D.; Valério, M.; Medina-Lopes, M.; Bergman, M.-L.; Gonçalves, J.; Demengeot, J.; Leite, R.B.; Lilue, J.; et al. Signatures in SARS-CoV-2 Spike Protein Conferring Escape to Neutralizing Antibodies. PLoS Pathog. 2021, 17, e1009772.

138. Mannar, D.; Saville, J.W.; Zhu, X.; Srivastava, S.S.; Berezuk, A.M.; Tuttle, K.S.; Marquez, C.; Sekirov, I.; Subramaniam, S. SARSCoV-2 Omicron Variant: ACE2 Binding, Cryo-EM Structure of Spike Protein-ACE2 Complex and Antibody Evasion.

139. Yuan, S.; Ye, Z.-W.; Liang, R.; Tang, K.; Zhang, A.J.; Lu, G.; Ong, C.P.; Poon, V.K.-M.; Chan, C.C.-S.; Mok, B.W.-Y.; et al. The SARS-CoV-2 Omicron (B.1.1.529) Variant Exhibits Altered Pathogenicity, Transmissibility, and Fitness in the Golden Syrian Hamster Model. bioRxiv 2022, 2022.01.12.476031.

140. Brinkkemper, M.; Brouwer, P.J.M.; Maisonnasse, P.; Grobben, M.; Caniels, T.G.; Poniman, M.; Burger, J.A.; Bontjer, I.; Oomen, M.; Bouhuijs, J.H.; et al. A Third SARS-CoV-2 Spike Vaccination Improves Neutralization of Variants-of-Concern. NPJ Vaccines 2021, 6, 146 .

141. Nawa, N.; Yamaoka, Y.; Koyama, Y.; Nishimura, H.; Sonoda, S.; Kuramochi, J.; Miyazaki, Y.; Fujiwara, T. Association between Social Integration and Face Mask Use Behavior during the SARS-CoV-2 Pandemic in Japan: Results from U-CORONA Study. Int. J. Environ. Res. Public Health 2021, 18, doi:10.3390/ijerph18094717.

142. IOC Tokyo 2020 Summer Olympics - Athletes, Medals \& Results Available online: https://olympics.com/en/olympicgames/tokyo-2020 (accessed on 6 December 2021).

143. Yang, W.; Shaman, J. COVID-19 Pandemic Dynamics in India, the SARS-CoV-2 Delta Variant, and Implications for Vaccination. medRxiv 2021, doi:10.1101/2021.06.21.21259268.

144. Griffin, J.B.; Haddix, M.; Danza, P.; Fisher, R.; Koo, T.H.; Traub, E.; Gounder, P.; Jarashow, C.; Balter, S. SARS-CoV-2 Infections and Hospitalizations Among Persons Aged $\geq 16$ Years, by Vaccination Status - Los Angeles County, California, May 1-July 25, 2021. MMWR Morb. Mortal. Wkly. Rep. 2021, 70, 1170-1176.

145. Prime Minister's Office; Street, 10 Downing Prime Minister Urges Caution as England Moves to Step 4 Available online: https://www.gov.uk/government/news/prime-minister-urges-caution-as-england-moves-to-step-4 (accessed on 6 December 2021).

146. Peeples, L. What the Science Says about Lifting Mask Mandates. Nature 2021, 593, 495-498.

147. UK Summary Available online: https://coronavirus.data.gov.uk (accessed on 7 December 2021).

148. CDC COVID Data Tracker Available online: https://covid.cdc.gov/covid-data-tracker (accessed on 7 December 2021). 
149. Ritchie, H.; Mathieu, E.; Rodés-Guirao, L.; Appel, C.; Giattino, C.; Ortiz-Ospina, E.; Hasell, J.; Macdonald, B.; Beltekian, D.; Roser, M. Coronavirus Pandemic (COVID-19). Our World in Data 2020.

150. WHO Coronavirus (COVID-19) Dashboard Available online: https://covid19.who.int (accessed on 7 December 2021).

151. Outbreak.info Available online: https://outbreak.info/ (accessed on 16 December 2021).

152. Grant, R.; Charmet, T.; Schaeffer, L.; Galmiche, S.; Madec, Y.; Von Platen, C.; Chény, O.; Omar, F.; David, C.; Rogoff, A.; et al. Impact of SARS-CoV-2 Delta Variant on Incubation, Transmission Settings and Vaccine Effectiveness: Results from a Nationwide Case-Control Study in France. Lancet Reg Health Eur 2021, 100278. 